\title{
Matching Energy Consumption and Photovoltaic Production in a Retrofitted Dwelling in Subtropical Climate without a Backup System
}

\author{
Sergio Gómez Melgar ${ }^{1, *(1)}$, Antonio Sánchez Cordero ${ }^{2}\left(\mathbb{C}\right.$, Marta Videras Rodríguez $^{2}{ }^{(D)}$ and \\ José Manuel Andújar Márquez ${ }^{1}$ (D) \\ 1 TEP192 Control y Robótica, Escuela Técnica Superior de Ingeniería, Universidad de Huelva, \\ CP. 21007 Huelva, Spain; andujar@uhu.es \\ 2 Programa de Ciencia y Tecnología Industrial y Ambiental, Escuela Técnica Superior de Ingeniería, \\ Universidad de Huelva, CP. 21007 Huelva, Spain; antonio.sanchez443@alu.uhu.es (A.S.C.); \\ martavideras@gmail.com (M.V.R.) \\ * Correspondence: sergomel@uhu.es
}

Received: 4 October 2020; Accepted: 16 November 2020; Published: 18 November 2020

\begin{abstract}
The construction sector is a great contributor to global warming both in new and existing buildings. Minimum energy buildings (MEBs) demand as little energy as possible, with an optimized architectural design, which includes passive solutions. In addition, these buildings consume as low energy as possible introducing efficient facilities. Finally, they produce renewable energy on-site to become zero energy buildings (ZEBs) or even plus zero energy buildings (+ZEB). In this paper, a deep analysis of the energy use and renewable energy production of a social dwelling was carried out based on data measurements. Unfortunately, in residential buildings, most renewable energy production occurs at a different time than energy demand. Furthermore, energy storage batteries for these facilities are expensive and require significant maintenance. The present research proposes a strategy, which involves rescheduling energy demand by changing the habits of the occupants in terms of domestic hot water (DHW) consumption, cooking, and washing. Rescheduling these three electric circuits increases the usability of the renewable energy produced on-site, reducing the misused energy from $52.84 \%$ to $25.14 \%$, as well as decreasing electricity costs by $58.46 \%$.
\end{abstract}

Keywords: minimum energy building; passive architecture; renewable energy on-site; energy efficiency; renewable energy potential factor

\section{Introduction}

The built environment, including infrastructure and buildings, has a huge environmental impact [1]. According to some studies, it amounts to $40 \%$ of primary energy use [2], which includes the production and transportation of materials, construction, and operation, as well as waste management. In recent years, strategies to reduce the impact of buildings have been proposed, these proposals involve the use of green building rating systems [3], however, their heterogeneity makes comparison between them difficult. On the contrary, it is easier to compare total energy use through gathered data that reach $80 \%$ in occupied buildings [4]. This is one of the reasons why the development of renewable energy systems (RESs) has been considered a priority to reduce greenhouse gas (GHG) emissions, and increase energy efficiency for the European Union in recent years [5].

Four different kinds of RES have demonstrated enough potential to be seriously considered within the European Union: Hydropower, wind, solar, and geothermal [6]. These RES can help reduce GHG emissions in the building sector. However, they may not be equally useful at different scales. 
For small-scale dwellings, especially when buildings are retrofitted, some of these RES are limited to the location of the building:

- Hydropower cannot normally be considered due to its scarcity.

- Geothermal needs enough ground availability [7], which is not usually accessible for urban residential buildings.

- Wind is influenced by other factors such as the shape of the building and the surrounding barriers. It is more seasonal and may disturb the neighbors [8].

- On the contrary, solar energy does not have these disadvantages.

Therefore, solar energy seems to be the most appropriate, specifically for subtropical climates. This is not only due to its small size, but also due to the fact that it features lower installation and operation costs [9] and takes advantage of the availability of solar radiation. The widespread use of photovoltaic (PV) modules as profitable RES has been restrained for several years, due to the lack of support from regulatory agencies in some countries. Meanwhile, other countries incentivize their installation [10], driven by low installation costs and self-consumption possibilities [11-13]. In the Spanish case, the number of PV arrays installed per year has varied widely, as a result of the lack of a consistent and clear support from regulatory agencies, even when this country, and the Andalusian region in particular, has a great potential for the installation of PV modules on roofs [14].

In terms of energy transactions, we are starting to move from traditional roles to new ones. Until now, occupants acted on one side of the grid solely as consumers, while electric companies performed the role of producers on the other side. However, this has been changing recently. For the Spanish market, a boost in small-scale RESs is expected due to the approval of the new Electric Energy Self-Consumption standard [15]. These new regulations about energy transactions would open new possibilities for tenants to move from traditional energy consumers to become energy prosumers [16].

This would imply a significant increase in the number of PV modules installed, especially in the residential sector $[17,18]$. In this new scenario, every dwelling connected to the grid could act as a prosumer, simplifying the energy exchange process with guaranteed prices. This would make the PV installation not only sustainable but also profitable. In this case, the need for RESs to install energy storage systems (ESSs) is reduced and it may only be contingent on a long-term economic analysis [17]. Even more if energy demand is aligned with energy production from RESs.

Another advantage is that energy produced from RES on-site has very low transmission losses when compared to energy from the grid produced off-site. This could produce a significant primary energy reduction for similar energy demands [19].

Dwellings which cannot be connected to the grid must deal with a deep balance analysis between energy produced (EP) and energy demanded (ED). Traditionally, these facilities have relied on a different kind of ESS, either battery-based electric storage or heat storage through a hot water tank $[11,20,21]$. Then, the higher the difference between EP and ED, the bigger the storage capacity must be. Therefore, installation and operational costs increase, which should be avoided to increase profitability. Additionally, an inadequate design of the ESS can lead to energy misuse (EM). As a consequence, ESS seems to be interesting only when there is no connection to the grid [11] or full energy coupling. The size of these ESS could then be reduced through the implementation of specific energy coupling measures [11,22].

A different approach can be seen in some studies suggesting that the introduction of smart appliances with building monitoring systems and control algorithms [23-25], was widely used several years ago, but not lately. Additionally, these high-tech measures may involve an extra cost, which could render them unaffordable for most dwelling tenants, especially in the case of social housing. Here, a simple and efficient operation of home appliances could be more convenient.

Other studies [26] suggest that the use of direct current (DC) instead of alternating current (AC) appliances can reduce energy losses through the improvement of their power factor, while increasing 
coupling factors with solar PV. However, the use of this method is not easy to expand due to the current configurations of electric facilities.

For both cases, whether dwellings are isolated or connected, great benefits can be obtained with the improvement of the energy coupling method. For isolated ones it will probably be best to reduce ESS, while for connected ones this can lead to a reduction in the consumption of energy from the grid (EG), which finally contributes to a primary energy use and lower electricity bills.

This paper aims to help dwelling tenants reschedule their energy demand for a smarter use of the PV energy produced. As a result, this improvement in energy coupling will provide a reduction in primary energy consumption and the associated electricity bill.

This approach promotes small low-budget electric installations to provide affordable solutions, in contrast with those based on electronic automatized controls, which may be more expensive for some tenants. For those with no access to smart appliances and building monitoring systems, this paper suggests some easily manageable rules of thumb that can be implemented by tenants to reduce primary energy consumption. Owners are provided with a labelling system, which helps them efficiently manage the operation of appliances.

In the research carried out, several commonly used concepts such as EP, ED, EG, and EM have been obtained and compared. Going further, they define a single expression to classify the efficiency of the coupling balance between the energy produced and energy demanded by a dwelling with a solar PV array. This is called the renewable potential factor (REPF), which expresses the amount of EP that is not efficiently used by the system and therefore, is finally misused. This REPF constitutes a novelty in this field and could highlight the capacity consumption of a dwelling to reduce the primary energy through a simple change in the habits of its occupants.

Specifically, this paper analyzes the case study of a social dwelling in Huelva (Spain), built before the first energy regulations appeared, but fully retrofitted in 2015 to achieve high energy efficiency standards. Based on the proposed case study, this paper analyzes results obtained across the most unfavorable winter week - where the available solar radiation is lower and climatization is needed to fulfil the following objectives:

- Evaluation of comfort conditions according to previous research.

- Analysis of different energy usage patterns.

- Evaluation of the validity of REPF as a useful tool for the characterization of zero energy buildings.

- Definition of several simple guidelines and a labelling system regarding when to use appliances.

- Evaluation of the economic impact of the suggested improvement.

This paper is structured as follows. In Section 2, the materials and methods used are explained. In Section 3, results of the current and suggested scenarios are shown and later discussed in detail in Section 4. Finally, the paper concludes with Section 5, where the main conclusions and findings are presented.

\section{Materials and Methods}

\subsection{Case Study}

The case study proposed involves a single apartment located within a residential building block in Huelva, see Figure 1. The obtained results can be applicable to other apartments with similar conditions. The case study unit has a usable area of $92.64 \mathrm{~m}^{2}$, while its built area including walls, partitions, etc. is $106.74 \mathrm{~m}^{2}$. The building is located at $37.2759^{\circ} \mathrm{N}$ and $6.9483^{\circ} \mathrm{W}$ and features a subtropical climate with mild winters and hot summers, defined as the Mediterranean Hot Summer climate according to Köppen's classification [27]. 


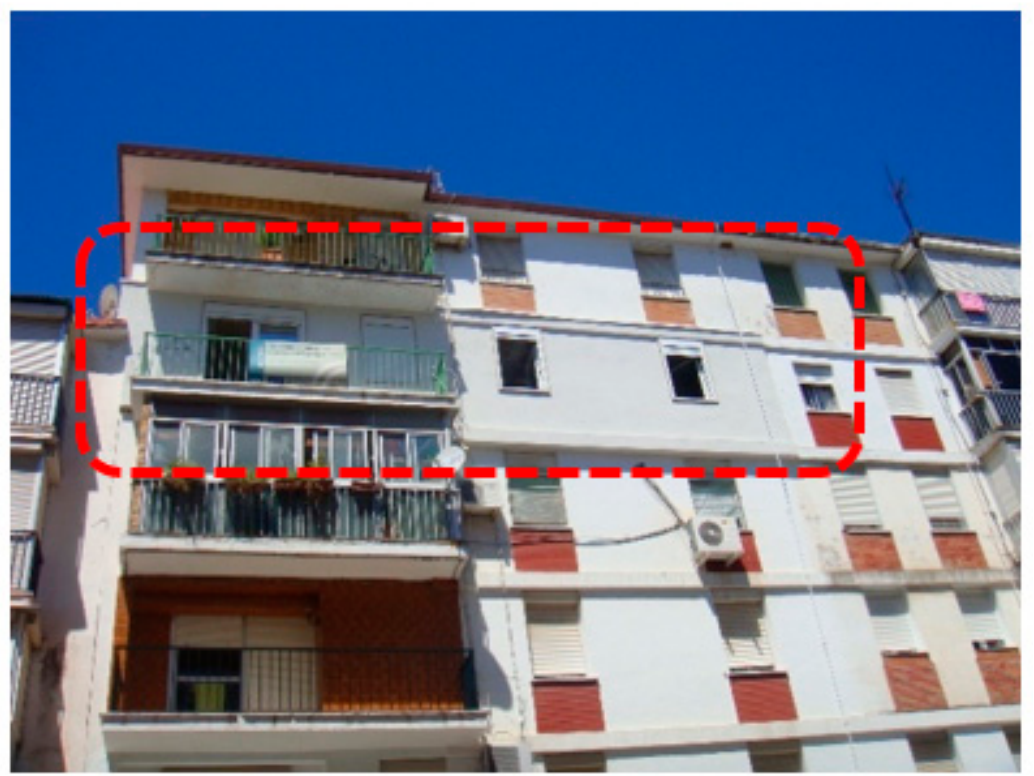

Figure 1. Building exterior view.

The building design and construction is dated in the early 1970s, many years before the enactment of the current Spanish Technical Code for residential buildings [28]. At that time, buildings provided low thermal comfort and high energy demand as some recent energy certification campaigns are showing [29].

Two dwellings of the mentioned building were fully retrofitted in 2015 following the University of Huelva Minimum Energy Building retrofit methodology (uhuMEBr) [30]. In short, this involves a refurbishment design and construction methodology to reduce the primary energy demand to under $80 \mathrm{kWh} / \mathrm{m}^{2}$ year. The methodology relies on the fulfillment of several design and facility parameters, as indicated in Table 1.

Table 1. Minimum energy buildings (MEBs) retrofitting design requirements. Summary from the University of Huelva Minimum Energy Building retrofit methodology (uhuMEBr) [30].

\begin{tabular}{cc}
\hline Design Parameters & Facility Parameters \\
\hline Sunshine & HAC systems $\leq 10 \mathrm{kWh} / \mathrm{m}^{2}$-year \\
$u$-value $<0.3 \mathrm{Wm}^{2} / \mathrm{K}$ & $\mathrm{DHW} \leq 90 \%$ renewable \\
Form factor $(\mathrm{F})<0.8 \mathrm{~m}^{2} / \mathrm{m}^{3}$ & Appliances $\leq \mathrm{A}++$ \\
N50-value $<0.6 \mathrm{~h}^{-1}$ & Lighting $\leq \mathrm{A}++$ \\
Sof $>0.05$ & Total primary energy demand $\leq 80 \mathrm{kWh} / \mathrm{m}^{2}$ year \\
No thermal bridges & HAS incorporated \\
Sgf $>0.1$ & RES incorporated \\
Heating and Air Conditioning $(\mathrm{HAC})$ energy & \\
demand $<10 \mathrm{kWh} / \mathrm{m}^{2}$ year & \\
\hline
\end{tabular}

The envelope, including walls and fenestration, was improved with additional insulation and an increase in airtightness. A heat recovery ventilation unit was installed to improve air quality without increasing heat losses. The RES installed is an array of $12 \mathrm{PV}$ modules (SACLIMA polycrystalline $265 \mathrm{Wp}$ each) from SaclimaTM, which makes up a $3 \mathrm{kWp}$ facility. EP is obtained in DC and converted into AC by an inverter Sunny Boy 2.0. The electronics of the PV installation come from AtersaTM. Initially, the PV array facility was not supported with ESS in alignment with the goal of this research, including coupling techniques without a battery-based backup system, as seen in Figure 2. Additionally, the energy exchange between small home producers and major electric grid companies was not regulated by the government at the time the retrofit was carried out. Therefore, when there was more EP from the PV array than ED by occupants, a certain amount of energy had to be wasted through an electric resistance 
on the roof. Recently, thanks to the approval of the new Spanish Electric Energy Self-Consumption standard, small home producers can exchange the EP, which is not needed by ED with electric companies. Additionally, several control devices have already been developed by the project's team such as the temperature meters, the thermal transmittance meter, and the home automation system (HAS) [31,32]. They provide real-time measures regarding temperature, relative humidity, and electric current in home circuits, as well as the PV array.

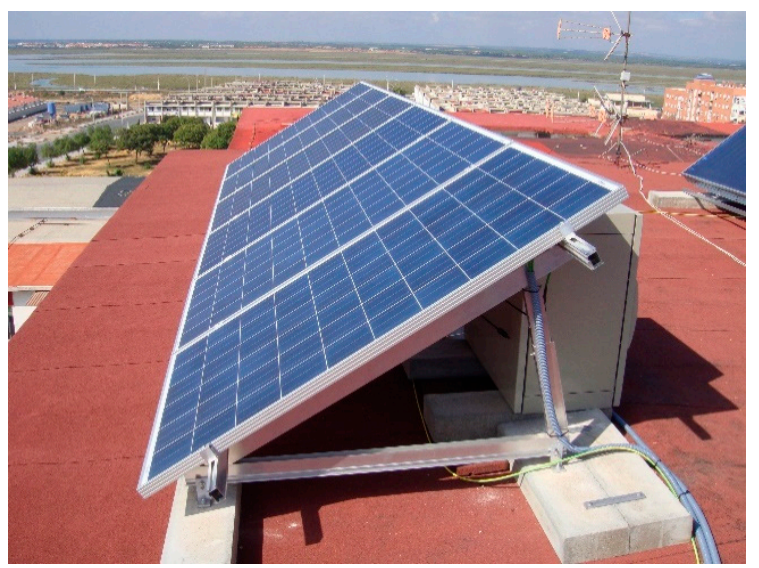

Figure 2. Several photovoltaic (PV) arrays on the roof.

The outside dry bulb temperature $(\mathrm{T})$ and relative humidity $(\mathrm{RH})$ are measured in the north-west and south-east facades of the building. Due to its relevance, the living room (Living) and the sleeping room (Sleeping) data have been chosen, instead of other less representative rooms. Both rooms have sensors to provide RH and T data at downward (T_d) and upward (T_u) positions (see Figure 3).

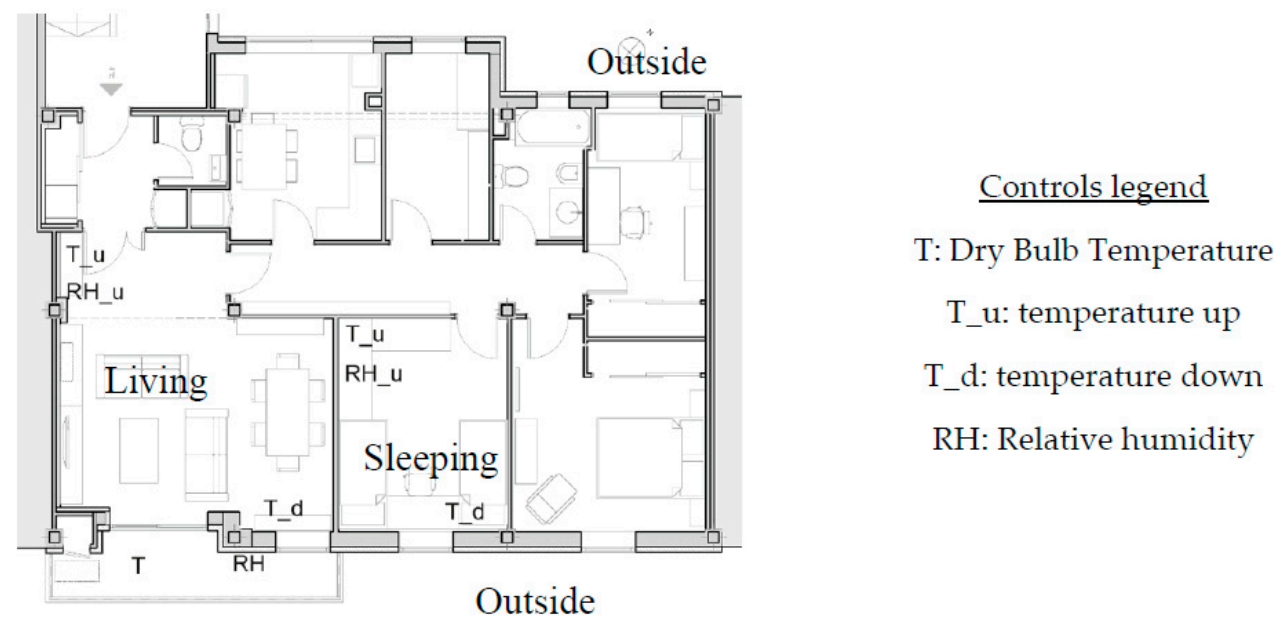

Figure 3. Control location within the case study.

Electric measuring devices for both production and demand can be measured independently at each of the electric circuits considered, while electricity produced by the PV array is measured in the DC/per PV module and AC at the inverter (see Table 2).

A family living in this dwelling includes five members: Two adults and three children. Occupation and scheduling are obviously different on workdays and holidays. However, both have been considered within this research, since holidays for children entail 184 out of 365 days of the year.

On workdays, all members of the family are out of the home from 08:00 to 15:00 due to school attendance or professional activities. However, housework is done by the cleaning staff. From 15:00 to 
20:00 no occupation pattern can be defined, while all members are usually at home from 20:00 to 08:00. Finally, no occupation pattern can be established during the holidays.

Table 2. Power factor and voltage considered for energy calculations.

\begin{tabular}{ccccc}
\hline Circuit & End Use & PF & V & Scheduled \\
\hline C1 & Domestic hot water (DHW) & 1.0 & 230 & $\bullet$ \\
C2 & Heat recovery (HR) & 0.5 & 230 & \\
C3 & Lighting & 0.5 & 230 & \\
C4 & Plugs & 0.7 & 230 & \\
C5 & Kitchen and Bath Plugs & 0.7 & 230 & \\
C6 & Cooking & 1.0 & 230 & $\bullet$ \\
C7 & Washing & 0.7 & 230 & $\bullet$ \\
C8 & Fridge & 1.0 & 230 & \\
C9 & Heating and Air conditioning (HAC) & 1.0 & 230 & \\
\hline
\end{tabular}

Note: $\bullet$ means circuits that can be rescheduled by dwelling users according to their living habits.

\subsection{Methodology}

This paper proposes modifying habits in the use of several home appliances to reduce the primary energy consumption for a typical winter week without an ESS. The methodology is organized into two different scenarios in order to be compared for the same week, from 7 to 13 January 2019.

- Scenario 1 describes energy performance in the case study according to data gathered from measuring devices. This includes EP from the PV array and the dwelling's ED.

- Scenario 2 provides for the same period, a proposal to reschedule the use of some appliances to reduce the mismatch between ED and EP and decrease the primary energy demand.

In order to operate with the rescheduling proposed in scenario 2, the electric installation in the dwelling has been organized into electric circuits from $\mathrm{C} 1$ to $\mathrm{C} 9$, as seen in Table 2. Some appliances such as water heaters, cooking appliances, and washing equipment can be easily rescheduled with the participation of the tenants, through direct use or with time controllers. These are included in circuits C1, C6, and C7. On the contrary, the rest of the circuits have not been rescheduled and remain unchanged. C2 controls the heat recovery unit, which functions $24 \mathrm{~h}$ a day. C3 controls the lighting system, which works mostly at night. C4 includes plugs, which are usually related to the electronic equipment for leisure time used mostly at night. $\mathrm{C} 5$ includes equipment from the kitchen and the bathroom, which is not included in C6. C8 includes the fridge, which must be on all day. $\mathrm{C} 9$ is connected to the HAC system, which is on all day to keep comfortable conditions, a requisite of the uhuMEBr.

Two strategies have been considered for the successful rescheduled circuits C1, C6, and C7. First, to provide the installation of timers in hot water heaters, washing machines, and dishwashers. Second, to include a labelling system with guidelines detailing the best times to use appliances in order to save energy and money.

Additionally, a cost-benefit analysis of the energy exchange is introduced to evaluate energy-saving options with the remaining EP that cannot be rescheduled. This is also an incentive for occupants to implement the rescheduling. The proposed rescheduling in the energy demand does not only concern environmental issues but also economic ones, which is even more significant for this social housing case study. Once ESS has been consciously avoided, this will be due to the existing possibility to exchange energy with the grid and thanks to the approval of the new Electric Energy Self-Consumption standard [15].

\subsubsection{Characterization of the Dwelling Coupling Balance and uhuMEBr}

Comfort data provided from the HAS are managed according to the following methodology: 
- Temperature data from inside, $\mathrm{Tu}$ and $\mathrm{Td}$, are used to obtain an average temperature (Tud) for both selected rooms: Living room and sleeping room, according to (1).

$$
\operatorname{Tud}=[(\mathrm{Tu}+\mathrm{Td}) / 2]\left({ }^{\circ} \mathrm{C}\right)
$$

- $\mathrm{Tu}, \mathrm{Td}$, and Tud data have been sampled in periods of $30 \mathrm{~min} . \mathrm{T}\left({ }^{\circ} \mathrm{C}\right)$ and $\mathrm{RH}$ data deviation are smooth enough to accept this reduction without significant affection.

- These data are plotted in a series of graphs with trend lines daily or on a weekly basis.

- Comfort data from other authors [33-35] about $\mathrm{T}\left({ }^{\circ} \mathrm{C}\right)$ and $\mathrm{RH}$ are also shown to compare with the data obtained in this case study.

Power (P) and energy (E) data cannot be directly obtained from the HAS. Therefore, some calculations must be made to obtain the required data: Current intensity (I), voltage (V), and power factor (PF). Real time I, is provided every $5 \mathrm{~s}$ by ammeters in each circuit:

- $\quad \mathrm{V}$ is measured by a voltmeter in each PV module and in the inverter.

- For grid electricity, $230 \mathrm{~V}$ has been presumed according to the electric company information.

- Finally, the PF at each circuit has been defined according to suggestions by other studies [36-38], as shown in Table 2.

Then, formulations can be operated to obtain power (2) and energy (3) per every electric circuit of the dwelling, as seen in the equations below:

$$
\begin{gathered}
\mathrm{Po}=\mathrm{Vo} \times \mathrm{Io} \times \cos \phi[\mathrm{W}] \\
\mathrm{E}(\mathrm{ti})=\int \mathrm{P}(\mathrm{t}) \mathrm{dt},[\mathrm{Wh}]
\end{gathered}
$$

Power produced (PP) and power demanded (PD) are obtained from the electric current data and provided from monitoring devices, while power misused (PM) and power from grid (PG) must be obtained through simple calculations. For most cases, PP from the PV array is not enough to cover PD. In that case, additional PG is necessary, as shown in Equation (4):

$$
\text { If } \mathrm{PP}<\mathrm{PD} \text {, then } \mathrm{PG}=\mathrm{PD}-\mathrm{PP}[\mathrm{kW}] \text {, and } \mathrm{PM}=0
$$

However, in some cases, PP is not needed by PD, then part of the energy is wasted to the environment and considered as misused (PM) or exchanged with the grid, which can be seen in the following Equation (5):

$$
\text { If } \mathrm{PP}>\mathrm{PD} \text {, then } \mathrm{PM}=\mathrm{PP}-\mathrm{PD}[\mathrm{kW}] \text {, and } \mathrm{PG}=0
$$

These $\mathrm{P}$ values can be transformed into E through the use of energy Equation (3), to obtain the primary energy according to Equation (6), which is affected by different conversion factors depending on whether the energy is coming from the PV source on-site (7) or from the grid (8). While the conversion factor from the on-site $\mathrm{PV}$ production $\left(\mathrm{CFp}_{1}\right)$ can be considered as 1 , the conversion factor from the grid $\left(\mathrm{CFp}_{2}\right)$ is 1.964 obtained from national electric data [19].

$$
\begin{gathered}
\text { Primary energy }=\left[\left((\mathrm{EP}-\mathrm{EM}) \times \mathrm{CFp}_{1}\right)+\left(\mathrm{EG} \times \mathrm{CFp}_{2}\right)\right], \\
\mathrm{CFp}_{1}=1, \\
\mathrm{CFp}_{2}=1.964
\end{gathered}
$$

All these results can be read in Section 4, figures containing P graphs show instant values with PP, PD, PM, and PG, while figures containing EP, ED, EM, and EG have been rearranged to show different measuring periods from $1 \mathrm{~h}$ to 1 full day. 
Finally, the REPF (9) is defined as a daily factor to show the grade of usability of a PV facility integrated in the University of Huelva Minimum Energy Building (uhuMEB). According to a defined time lapse, it shows the relation between two energy parameters: EM and EP.

$$
\mathrm{REPF}=[(\mathrm{EM} / \mathrm{EP}) \times 100](\%)
$$

With the comparison of REPF values in scenarios 1 and 2, the performance of the RES can be determined.

\subsubsection{Coupling Improvement through Rescheduling Options and the REPF}

This paper establishes the comparison of two different scenarios to reduce the primary energy demand according to uhuMEBr [30]. While scenario 1 is based on experimentation, scenario 2 is based on a simulation through several electric circuits, which are rescheduled to change the PD distribution throughout the day. Users are encouraged to change some habits in order to concentrate on PD during the peak production from PV. Finally, EP and ED remain the same from scenario 1 to scenario 2, but EM and EG are reduced, as well as the REPF.

In scenario 2, appliances on circuits $\mathrm{C} 1, \mathrm{C} 6$, and $\mathrm{C} 7$ are affected by rescheduling through the conscious use of timers and controls on those appliances, which can be automatized such as the dishwasher, washer, and water heaters, while other appliances used for cooking rely on occupants' willingness to reduce ED. This case study relies on house staff availability.

According to the objective of the paper, the PD hourly distribution is modified for every circuit according to the most representative PD patterns for the typical appliances on it, and the most convenient use time for occupants:

- $\quad$ C7, laundry between 10:30 and 12:30.

- C6, cooking between 12:30 and 14:30.

- $\quad$ C7, dishwasher between 14:30 and 15:30.

- $\quad$ C1, water heater between 15:30 and 17:30.

PD for scenario 2 (PDe2) can be obtained according to Equations (10) and (11), where PDe2 from circuits $\mathrm{C} 1, \mathrm{C} 6$, and $\mathrm{C} 7$ changes from PDe1, while it remains the same for the rest of the circuits.

$$
\begin{gathered}
\operatorname{PDe} 2(\mathrm{i})=\sum_{\mathrm{i}=1}^{\mathrm{n}}\left(\mathrm{Vo}_{\mathrm{i}} \times \mathrm{Io}_{\mathrm{i}} \times \cos \phi_{\mathrm{i}}\right) \\
\text { PDe2 }(\mathrm{i})=\sum_{\mathrm{i}=1}^{\mathrm{n}} \operatorname{PDCi}
\end{gathered}
$$

This way, the PD displacement from PDe1 to PDe2 will provide a PG variation from PGe1 to PGe2 and a PM from PMe1 to PMe2. Furthermore, they will be converted to a modification of EG, from EGe1 to EGe2 and EM from EMe1 to EMe2. Finally, the REPF provides a similar reduction from REPFe1 to REPFe2. The lower the factor, the more effective the PV production is. On the contrary, the higher the factor, the less effective and more suitable it is to improve energy coupling.

\subsubsection{Energy Cost Analysis}

Finally, an energy cost analysis has been conducted through a comparison between EG and EM, in both scenarios 1 and 2. EG produces costs from the grid (ECG), while EM generates income from misused energy (EIM), which should be balanced. Information about the energy unit cost (EC) has been obtained through information gathered from the tenants' energy bills and the national market of electricity price [39].

$$
\text { Cost e1,2(i) }=\sum_{\mathrm{i}=1}^{\mathrm{n}}\left(\mathrm{EGo}_{\mathrm{i}} \times \mathrm{ECGo}_{\mathrm{i}}\right)-\left(\mathrm{EMo}_{\mathrm{i}} \times \mathrm{EIMo}_{\mathrm{i}}\right)
$$




\subsubsection{Labelling When to Use Guide Instructions}

Conclusions obtained from the results section have been used to provide an easy When to Use labelling system, (Figure 4 shows an example). These labels include:

- Appliance description.

- Aim of the rescheduling.

- Energy coupling potential.

- Rescheduling proposal.

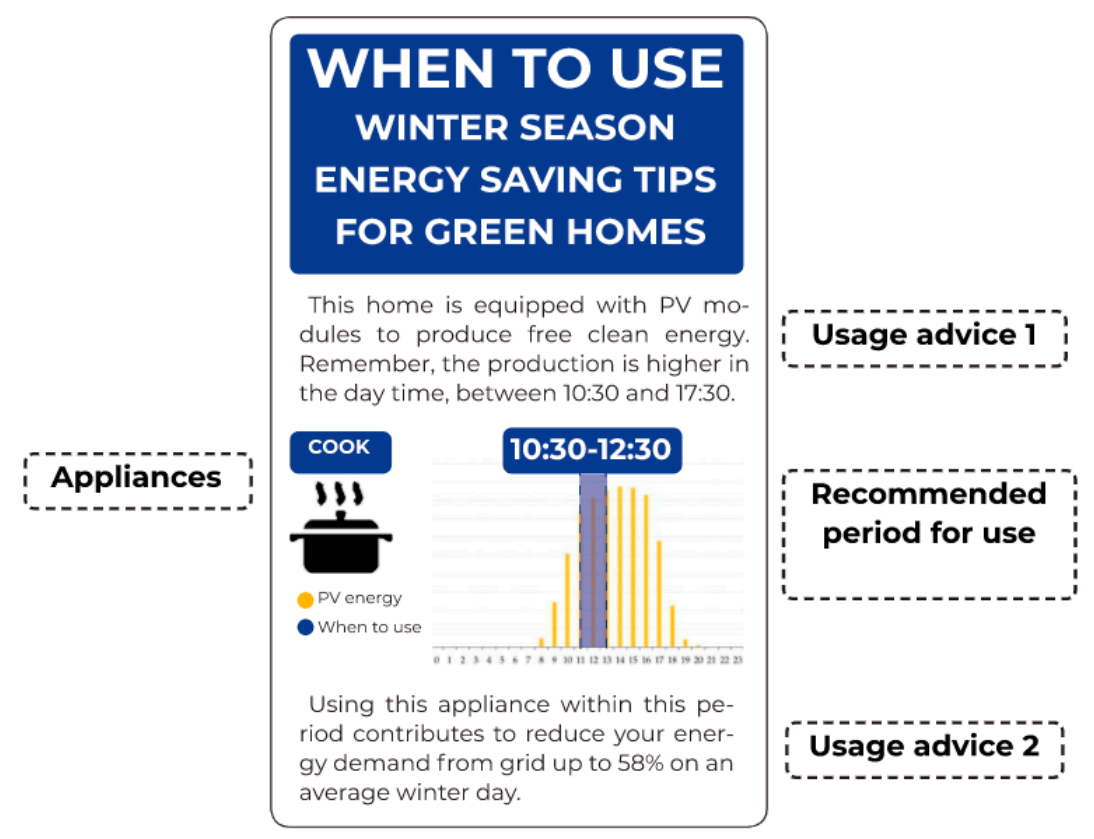

Figure 4. The When to Use labelling system example.

\section{Results}

According to the methodology explained in Section 2, Section 3 provides a comprehensive review of two different scenarios of primary energy consumption for a typical winter week between 7 and 13 January 2019.

\subsection{Evaluation of Comfort Conditions}

Before proceeding with further analyses of energy balance, comfort data from sleeping and living rooms are shown in Figures 5 and 6. Here, comparisons between indoor comfort data and comfort ranges defined by other studies are included.

Although $\mathrm{T}^{\circ}$ has been defined as the most important parameter to validate thermal comfort [35], also RH should be considered here. Extreme RH can provide a certain level of discomfort even when $\mathrm{T}^{\circ}$ remains between comfort ranges.

In terms of short-term occupation, very low RH values are associated with some health issues such as dry eye, while a high RH has influence on people's metabolic comfort [35]. Therefore, RH comfort ranges should be between 45-55\% [40], according to the American Society of Heating, Refrigerating, and Air-Conditioning Engineers, or between 30-80\% [35], according to suggestions from the Chartered Institution of Building Services Engineers. 


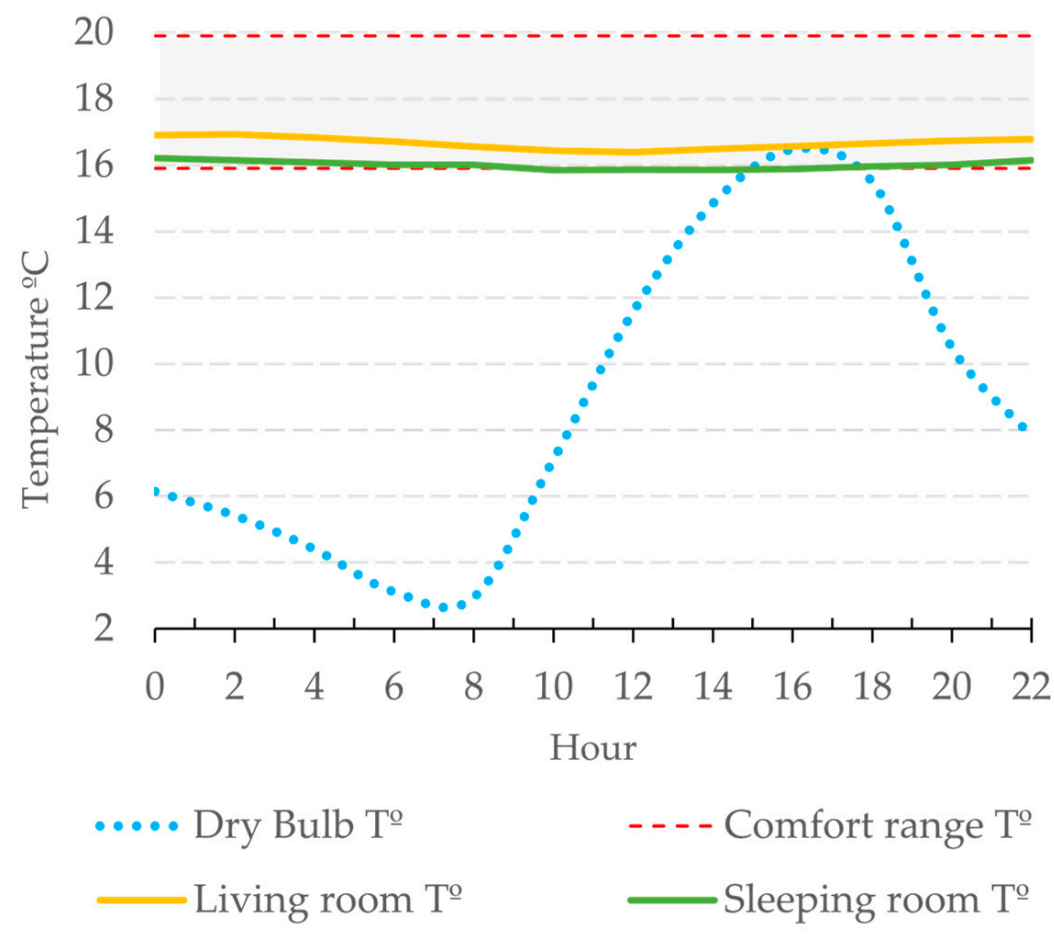

Figure 5. Temperature analysis of an average day in ${ }^{\circ} \mathrm{C}$.

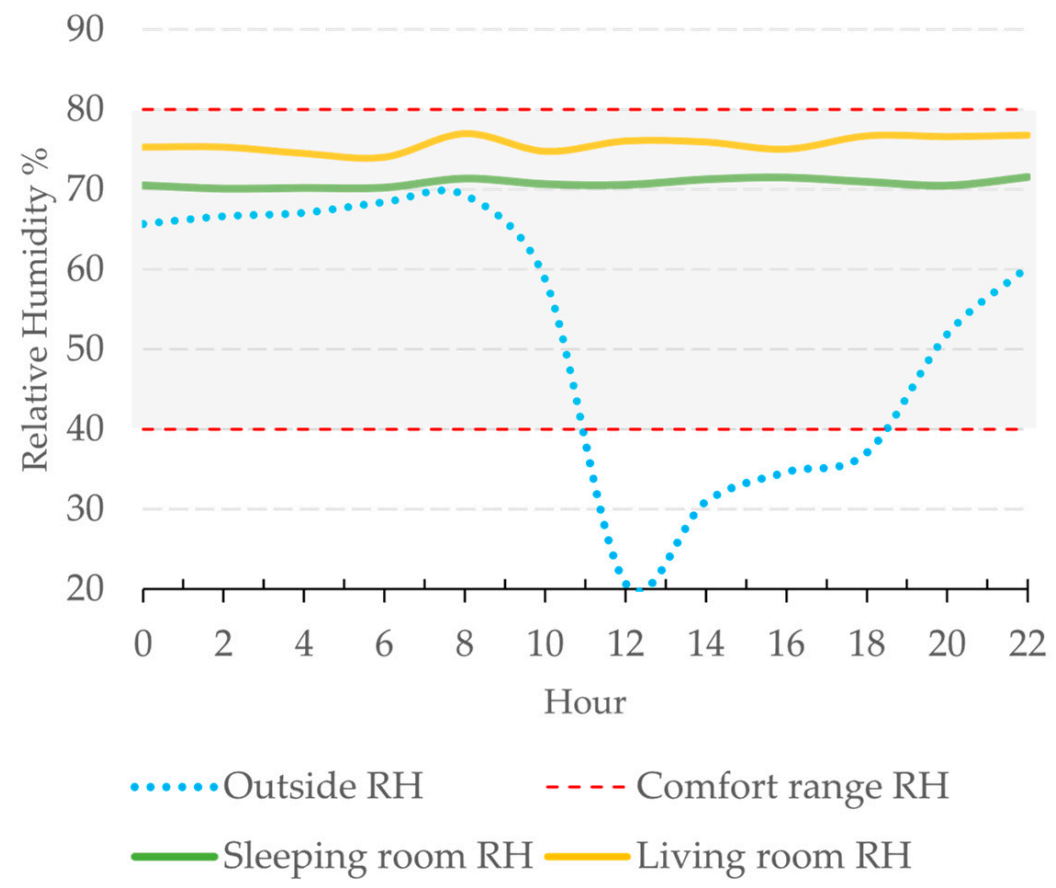

Figure 6. The relative humidity $(\mathrm{RH})$ analysis of an average day in $\%$.

For a long-term occupation, very high $\mathrm{RH}$ values inside a dwelling can stimulate the appearance of some construction pathologies and other health issues in occupants [34,35,41]. Therefore, RH comfort ranges should be below 60\%, according to The Environmental Protection Agency [34], or below $70 \%$ [35], according to CIBSE. This would reduce the risk of mold-related diseases and those associated with volatile organic compounds.

However, all these are recommendations to maintain indoor comfort, rather than mandatory regulations. 


\subsubsection{Temperature Analysis}

Several $\mathrm{T}^{\circ}$ results are shown in Figure 5, including outdoor and indoor $\mathrm{T}$ values, as well as adaptive $\mathrm{T}$ comfort ranges.

The blue line represents the outdoor weather dry bulb temperature $\mathrm{T}^{\circ}$, while the yellow and green lines represent living and sleeping rooms $\mathrm{T}^{\circ}$. Red lines and the grey zone show the comfort range for a dwelling with $\mathrm{HAC}$ between 15.9 to $19.9^{\circ} \mathrm{C}$. $\mathrm{T}^{\circ}$ comfort ranges have been obtained from the adaptive algorithm methodology [33] considering a mix mode ventilated building with HAC and free cooling, while the RH comfort range has been obtained from relevant design guides [34,35].

DBT achieves comfort conditions most of the time, while $\mathrm{T}^{\circ}$ in the living and sleeping rooms remain comfortable through the day. This demonstrates that the uhuMEBr retrofit is working properly for this dwelling. The living room average $\mathrm{T}^{\circ}$ remains between 16.33 and $16.89^{\circ} \mathrm{C}$, while the sleeping room $\mathrm{T}^{\circ}$ remains between 15.81 and $16.21{ }^{\circ} \mathrm{C}$. Note that the average temperatures within the living room are slightly higher than those in the sleeping room, but the difference remains circa $0.5{ }^{\circ} \mathrm{C}$ and between the comfort ranges suggested from adaptative comfort theories [33].

\subsubsection{Relative Humidity Analysis}

Figure 6 presents the RH for a typical average winter weekday, between 7 and 13 January 2019, including indoor and outdoor conditions, as well as comfort ranges.

The blue line represents the outdoor $\mathrm{RH}$, while the yellow and green lines represent $\mathrm{RH}$ in living and sleeping rooms. The grey zones between red lines show the comfort range, which is between $40 \%$ and $80 \%$ [35].

According to Figure 6, the outdoor RH displays significant variations during the day, from $20.70 \%$ to $69.28 \%$. It remains between comfort ranges at all times except during the 11:00 to 18:00 period. On the contrary, the indoor RH measured in the living and sleeping rooms is quite constant with values between $70.15 \%$ and $76.97 \%$.

The results for each analysis show how both $\mathrm{T}^{\circ}$ and $\mathrm{RH}$ seem to remain between comfort ranges, although RH should be reduced for long-time occupation due to possible health issues and construction pathologies. Considering $\mathrm{T}$ data, the retrofit work can be successfully considered to accomplish uhuMEBr, which is the first step to proceed with further energy comparisons to fully demonstrate compliance with the method. Variations in $\mathrm{T}^{\circ}$ and $\mathrm{RH}$, from scenario 1 to scenario 2 are not expected since HAC does not adhere to the rescheduling proposal.

\subsection{Primary Energy Consumption in Scenario 1}

\subsubsection{Daily Energy Analysis in Scenario 1}

A summary of daily energy data has been plotted in Figure 7 and Table 3 to compare the energy coupling potential. Figure 7 contains a bar graph to show EP, ED, EG, EM, and the insolation measured on-site to confirm the energy produced by the PV modules, while Table 3 contains their numbers.

According to Table 3, the EP per day is between 10.40 to $14.40 \mathrm{kWh}$ with a $12.13 \mathrm{kWh}$ average, while the ED per day is between 8.88 to $20.87 \mathrm{kWh}$ with a 13.28 average. According to these EP and ED daily figures, the EG and EM results shown vary greatly. The EGe1 per day is between 4.98 to $12.67 \mathrm{kWh}$ with a 7.57 average, while the EM per day is between 2.35 to $10.68 \mathrm{kWh}$ with a 6.41 average. Although it is difficult to obtain a clear pattern from the analysis of these numbers, some rules can be defined: Each day needs EP and EG, but EMe1 has very different results. The average primary energy demand e1 is $20.73 \mathrm{kWh} /$ day, therefore, $0.23 \mathrm{kWh} / \mathrm{m}^{2}$ day per square meter. Finally, REPFe1 ranges from $22.27 \%$ on Wednesday to $74.17 \%$ on Saturday. Moreover, according to Table 3, REPFe1 is lower from Monday to Thursday and higher from Friday to Sunday. 


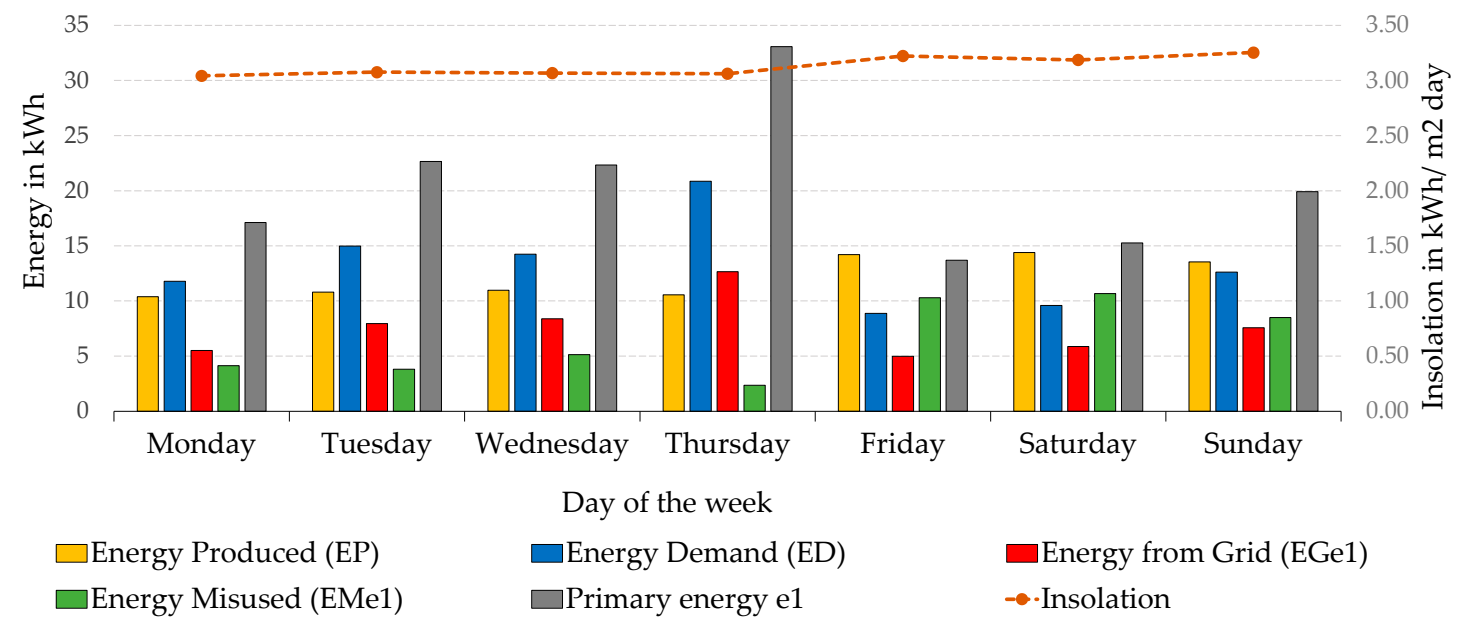

Figure 7. Daily horizontal insolation and energy analysis: Energy produced (EP), energy demand (ED), energy from grid (EGe1), and energy misused (EMe1) in scenario 1.

\subsubsection{Hourly Energy Analysis in Scenario 1}

A summary of hourly energy data for an average day, from 7 to 13 January 2019, has been plotted in Figure 8 and Table 4 to compare the hourly coupling potential in an average weekday. Figure 8 contains graph bars to show EP, ED, EGe1, and EMe1, while Table 4 contains their figures.

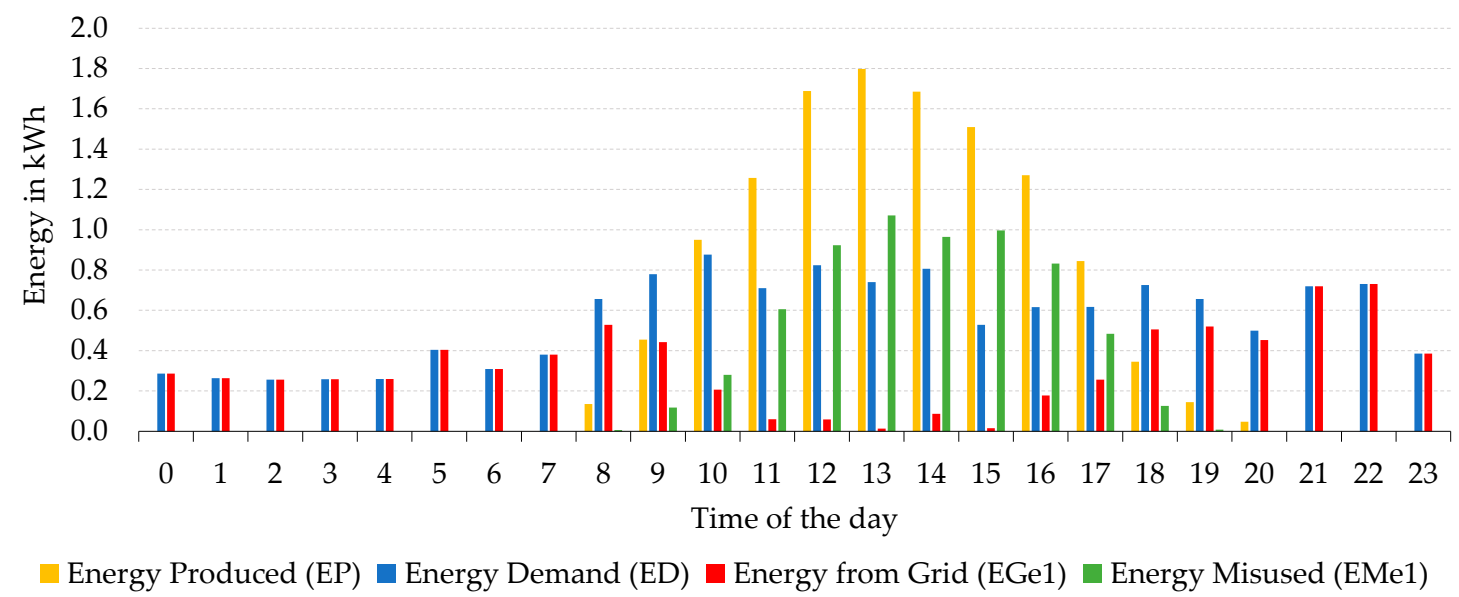

Figure 8. Hourly energy analysis for an average weekday in scenario $1 \mathrm{in} \mathrm{kWh}$.

According to Figure 8 and Table 4, significant amounts of EP and EMe1 appear only during the daytime, in the period between 08:00 and 18:30, while the most representative EP appears between 10:30 and 17:30.

On the contrary, ED is unsteady during the day. Consequently, EGe1 is higher in the mornings and evenings, but low in the early morning and almost non-existent around noon and early afternoon. EMe1 only appears from 10:30 to 17:30 as expected. There is neither EP nor EMe1 from 20:00 to 08:00, while the rest of the day provides enough to be rescheduled to reduce EGe1. On the contrary, EGe1 is non-existent when EP is at its maximum, which occurs from 11:00 to 18:00, representing a potential to improve the energy coupling rescheduling ED from 19:00 to 08:00.

Data from Figure 8 have been used to set six periods of daytime energy values with similar energy patterns and results are shown in Table 4. 
Table 3. Daily energy analysis: EP, ED, EGe1, EMe1 in kWh, renewable energy potential factor (REPFe1) in \%, and insolation in kWh $/ \mathrm{m}^{2}$ day.

\begin{tabular}{|c|c|c|c|c|c|c|c|c|}
\hline & Monday & Tuesday & Wednesday & Thursday & Friday & Saturday & Sunday & Average \\
\hline $\mathrm{EP}(\mathrm{kWh})$ & 10.40 & 10.81 & 10.98 & 10.55 & 14.20 & 14.40 & 13.55 & 12.13 \\
\hline ED (kWh) & 11.79 & 14.97 & 14.25 & 20.87 & 8.88 & 9.60 & 12.62 & 13.28 \\
\hline EGe1 (kWh) & 5.52 & 7.97 & 8.40 & 12.67 & 4.98 & 5.88 & 7.57 & 7.57 \\
\hline $\begin{array}{c}\text { EMe1 (kWh) } \\
\text { Primary }\end{array}$ & 4.13 & 3.81 & 5.13 & 2.35 & 10.29 & 10.68 & 8.50 & 6.41 \\
\hline $\begin{array}{c}\text { Energy e1 } \\
(\mathrm{kWh})\end{array}$ & 17.11 & 22.65 & 22.34 & 33.08 & 13.69 & 15.27 & 19.92 & 20.73 \\
\hline REPFe1 (\%) & 39.71 & 35.25 & 46.72 & 22.27 & 72.46 & 74.17 & 62.73 & - \\
\hline $\begin{array}{c}\text { Insolation } \\
\left(\mathrm{kWh} / \mathrm{m}^{2} \text { day }\right)\end{array}$ & 3.04 & 3.08 & 3.07 & 3.06 & 3.22 & 3.19 & 3.25 & 3.13 \\
\hline
\end{tabular}

Table 4. Hourly energy analysis: EP, ED, EGe1, EMe1 in kWh, and REPFe1 in \% for scenario 1.

\begin{tabular}{cccccccc}
\hline Indicator/Period & $\mathbf{0 0 : 0 0 - 0 4 : 0 0}$ & $\mathbf{0 4 : 0 0 - 0 8 : 0 0}$ & $\mathbf{0 8 : 0 0 - 1 2 : 0 0}$ & $\mathbf{1 2 : 0 0 - 1 8 : 0 0}$ & $\mathbf{1 8 : 0 0 - 2 0 : 0 0}$ & $\mathbf{2 0 : 0 0 - 2 4 : 0 0}$ & $\mathbf{0 0 : 0 0 - 2 4 : 0 0}$ \\
\hline EP $(\mathrm{kWh})$ & 0.00 & 0.00 & 2.79 & 6.68 & 2.60 & 0.05 \\
EDe1 $(\mathrm{kWh})$ & 1.06 & 1.35 & 3.02 & 2.90 & 2.61 & 12.13 \\
EGe1 $(\mathrm{kWh})$ & 1.06 & 1.35 & 1.24 & 0.17 & 1.46 & 2.33 \\
EMe1 $(\mathrm{kWh})$ & 0.00 & 0.00 & 1.01 & 3.96 & -29 & 0.00 \\
REPFe1 $(\%)$ & - & - & - & - & - & 5.41 \\
\hline
\end{tabular}




\subsubsection{Power Analysis in Scenario 1}

This section evaluates the possibilities of reducing REPF and primary energy demand by comparing power graphs of an average day, from 7 to 13 January 2019: PP in yellow, PDe1 in blue, PGe1 in red, and PMe1 in green.

PP and PDe1 are shown in Figure 9. Here, PP shows a bell pattern with some irregularities starting at 08:00 and finishing after 20:00. The PP peak can be seen around noon from 12:00 to 16:00, with figures from 1400 to 1800 watts (W). Consequently, this can be defined as the most convenient period for PV production. On the contrary, the PDe1 pattern shows two different trends: One from 00:00 to 08:00, with a quasi-constant state of around $300 \mathrm{~W}$ demand, while a second from 08:00 to 00:00 features very irregular figures from 400 to $1000 \mathrm{~W}$.

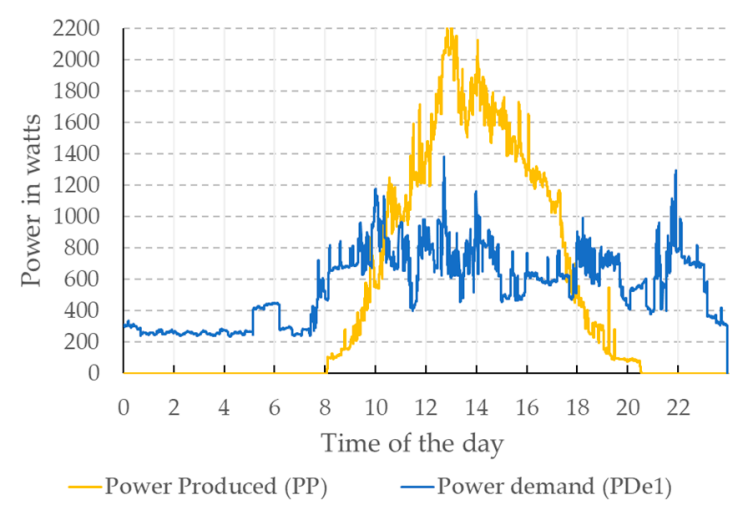

Figure 9. Power demand vs. production in scenario 1.

Figure 10 contains data in $\mathrm{W}$ of PGe1 and PMe1. PMe1 peak values are lower than PPe1, but their pattern is slightly similar. The PMe1 starting time is close to 10:00 and ends close to 18:00. The peak PMe1 can be also seen around noon from 12:00 to 16:00, with figures between 800 to $1200 \mathrm{~W}$ of misused power. On the contrary, the pattern for PGe1 is totally irregular and features periods with no demand against others with high figures. As seen in Figure 10, PP has effects on PMe1, therefore, at the time of the day with no PP, the PDe1 and PGe1 are similar.

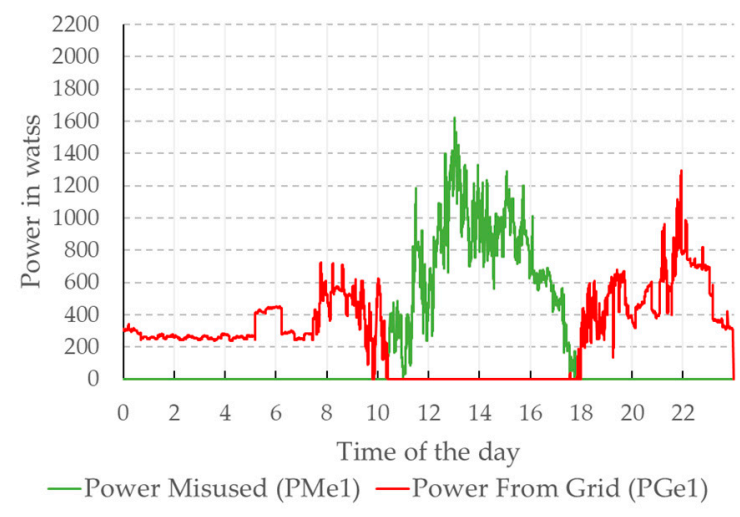

Figure 10. Power grid vs. misused in scenario 1.

Since PDe1 is the only one suitable for modification by the occupant, it is useful to propose when to use rules for domestic appliances. Other power items such as PP and PG cannot be modified without a significant economic investment, therefore, they have not been considered in this paper. 


\subsubsection{Power Breakdown Analysis in Scenario 1}

Figure 11 shows a power breakdown for a typical day, according to the electric circuits of the dwelling (see Table 2). Here, results are plotted into a logarithm in the Y axis, while a linear scale is used from 00:00 to 23:00 $\mathrm{h}$ in the $\mathrm{X}$ axis. All electric circuits, from $\mathrm{C} 1$ to $\mathrm{C}$, have been plotted.

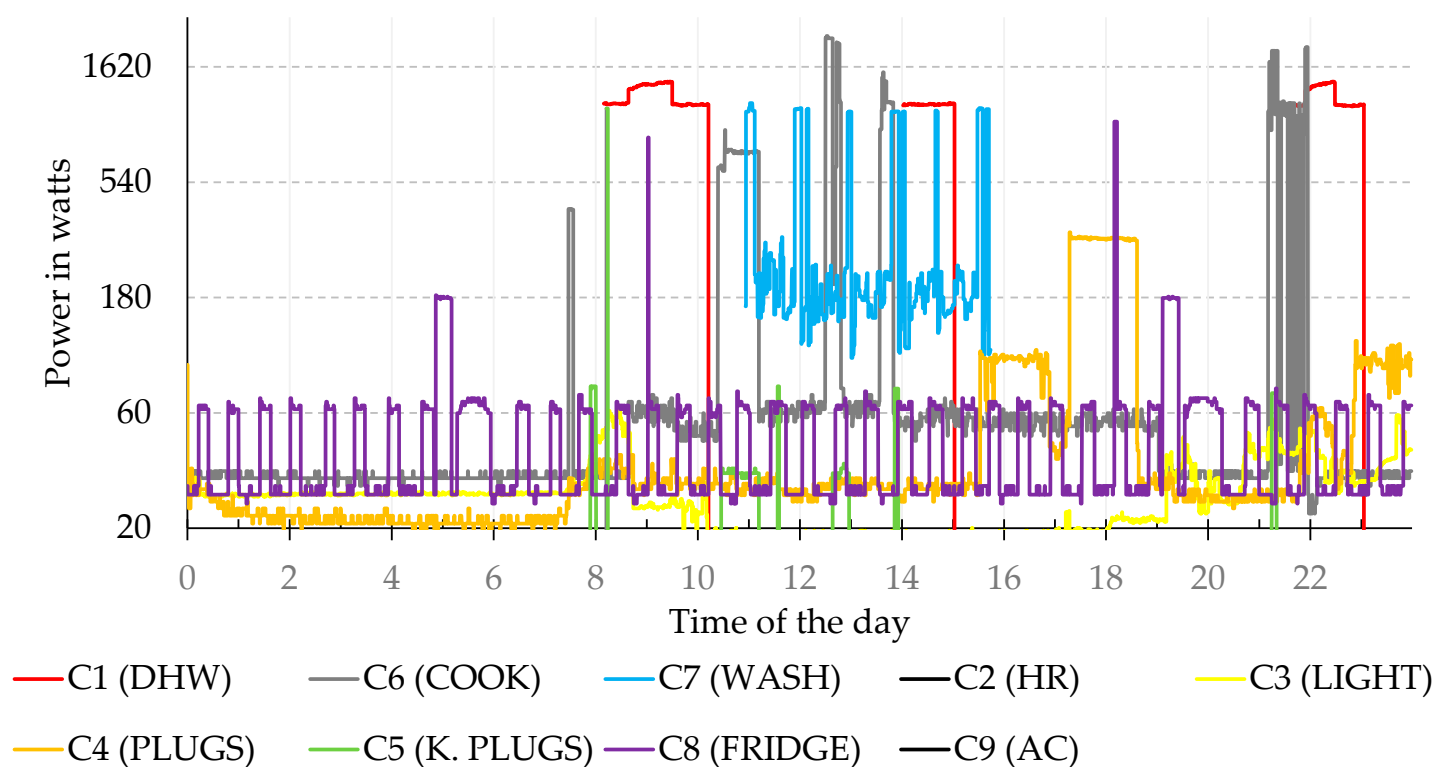

Figure 11. Power by circuits breakdown on Sunday the 13th for scenario 1 in watts.

Circuits $\mathrm{C} 1, \mathrm{C} 6$, and $\mathrm{C} 7$ seem to show the highest power values, while $\mathrm{C} 2, \mathrm{C} 3$, and $\mathrm{C} 9$ show the lower ones. Other circuits such as $\mathrm{C} 4$ and $\mathrm{C} 8$ show a significant relevance as well, with $\mathrm{C} 4$ and $\mathrm{C} 8$ being used throughout the day. This PD breakdown seems consistent with the assumptions made in the Methods Section. Specifically, C1, C6, and C7 have a crucial importance when production and demand coupling is the objective.

The $\mathrm{C} 1$ circuit-domestic hot water (DHW) is turned on in irregular periods from 08:00 to 10:00, 14:00 to 15:00, and 21:00 to 23:00 at a constant rate of close to $1400 \mathrm{~W}$, which is consistent with electric device requirements.

The $\mathrm{C} 6$ circuit-cooking appliances (COOK) is used in short periods (of less than $1 \mathrm{~h}$ each), several times in the morning, noon, and evening.

The C7 circuit - washing devices (WASH) is used mainly from 10:00 to 16:00 at a variable rate with a peak of $1200 \mathrm{~W}$, but it can certainly be used at night on different days of the same week.

\subsubsection{Power Analysis in Scenario 1 by Scheduling Options}

As can be seen in Figure 11, circuits C1, C6, and C7 show very irregular patterns, which can be rescheduled. As a result, and according to the description of the case study in Section 2, circuits C1, C6, and C7 have been grouped into power scheduled circuits (PS), while the other circuits remain defined as power others (PO). In Figure 12, PSe1, POe1, and PMe1 have been plotted to explain the portion of PDe1 that can be rescheduled to reduce PMe1 and which cannot. PSe1 is plotted in light blue, POe1 in dark blue, and PMe1 in green.

The PMe1 plotted here is similar to the one shown in Figure 10 and represents the instant power from renewable sources, which is not used by the dwelling. It has a value of zero during almost the entire period studied, except from 10:30 to 17:30. However, PS and PO during that period are not enough to take advantage of all the PMe1 available. 


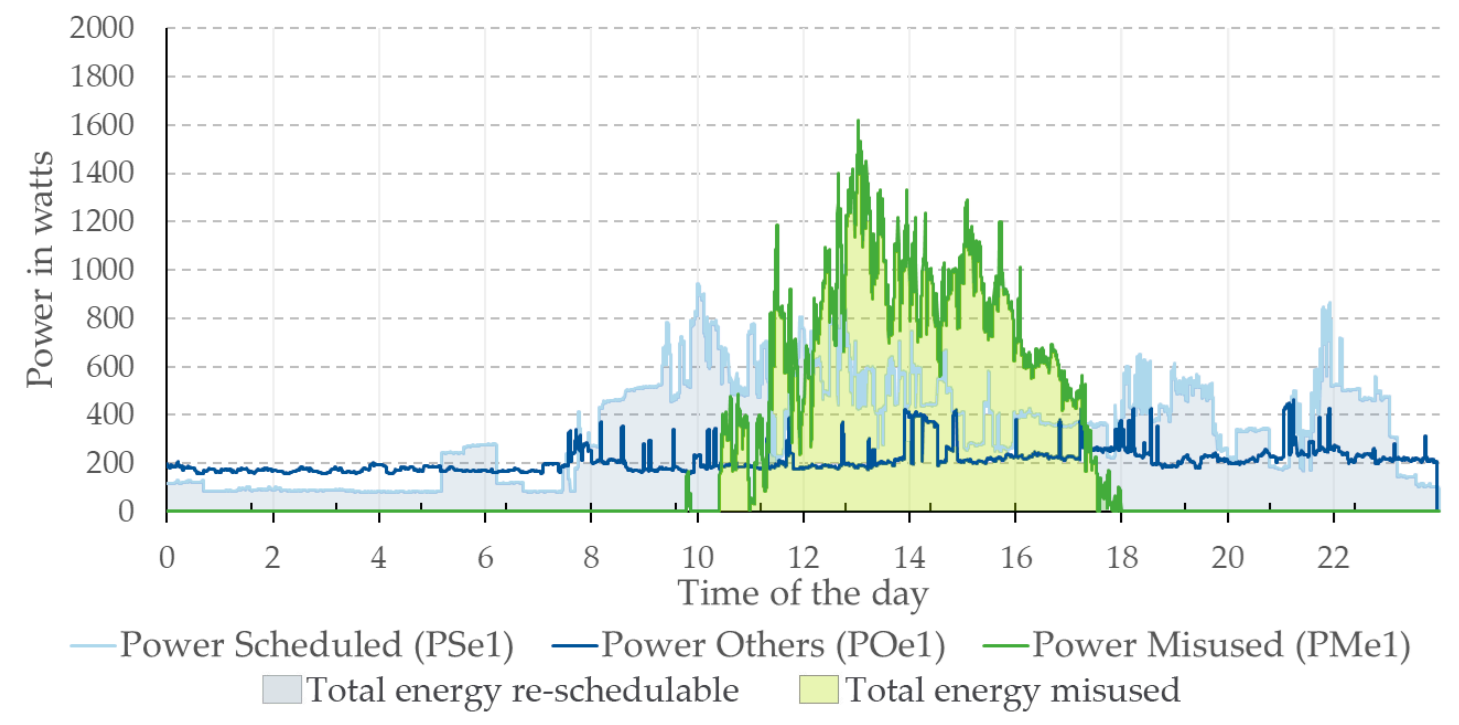

Figure 12. Power, scheduled (PSe1) vs. other circuits (POe1) and misused (PMe1) for scenario 1 in watts.

As seen in Figure 12, PSe1 and POe1 show very different patterns, which enhance the idea to proceed with the rescheduling of PSe1 instead of POe1, while the PSe1 graph line shows great variations. On the contrary, POe1 remains low and almost constant.

The area contained between the PMe1 and PSe1 graph lines shows the renewable power that can be used in case it can be displaced from the 8:00 to 10:30 and 17:30 to 23:00 intervals. Therefore, what PSe1 shows in Figure 12 is the P pattern that should be modified by a rescheduling of the dwelling occupants' habits, in order to reduce the primary energy demand in a simple and effective way.

\subsection{Primary Energy Demand in Scenario 2}

Circuits $\mathrm{C} 1, \mathrm{C} 6$, and $\mathrm{C} 7$ have been rescheduled according to the methodology explained in Section 2. This configures a new scenario known as number 2. The PDe1 pattern has been reorganized into a new PDe2 to increase coupling with PMe1 from the PV array. This provides a significant reduction in the primary energy demand that fulfils the requirements of the uhuMEBr methodology [29] (under $80 \mathrm{kWh} / \mathrm{m}^{2}$ year). Circuits C2, C3, C4, C5, C8, and C9 remain unchanged in scenario 2.

\subsubsection{Hourly Energy Analysis in Scenario 2}

A summary of the hourly energy data is shown in Figure 13 and Table 5 to present the coupling results in scenario 2. Figure 13 is a bar graph that shows EPe2, EDe2, EGe2, and EMe2, while Table 5 contains their numerical values.

According to Figure 13, a significant part of the EDe1 shown in scenario 1 has been rescheduled from 10:30 to 17:30. This has produced a reduction in EMe2 and EGe2 for the rest of the day. Although EMe2 is still available, it cannot be used further since other circuits different from C1, C6, and C7 are not suitable to be rescheduled in the same way.

According to Table 5, in scenario 2 the energy data has suffered several improvements. First, there is a reduction in both EGe2 and EMe2. EG changes from $7.57 \mathrm{kWh}$ at EGe1 to $4.21 \mathrm{kWh}$ at EGe2. Second, EM changes from $6.41 \mathrm{kWh}$ at EMe1 to $3.05 \mathrm{kWh}$ at EMe2. This reduction is shown as a variation of EG (VEG) and EM (VEM). The VEG reduction provided has been $44.38 \%$ and VEM is reduced in $52.41 \%$. Finally, the REPF changes from $52.84 \%$ at REPFe 1 to $25.14 \%$ at REPFe2. The equation $\mathrm{ED}+\mathrm{EG}=\mathrm{ED}+\mathrm{EM}$ is fulfilled for the whole interval. 
Table 5. Hourly energy analysis: Comparison between scenarios 1 and 2 .

\begin{tabular}{|c|c|c|c|c|c|c|c|}
\hline Indicator/Period & 00:00-04:00 & 04:00-08:00 & 08:00-12:00 & 12:00-18:00 & 18:00-20:00 & 20:00-24:00 & 00:00-24:00 \\
\hline $\mathrm{EP}(\mathrm{kWh})$ & 0.00 & 0.00 & 2.79 & 6.68 & 2.60 & 0.05 & 12.13 \\
\hline REPFe1 (\%) & - & - & - & - & - & - & $52.84 \%$ \\
\hline \multicolumn{8}{|c|}{ Affected by Rescheduling } \\
\hline EDe1 (kWh) & 1.06 & 1.35 & 3.02 & 2.90 & 2.61 & 2.33 & 13.28 \\
\hline EDe2 (kWh) & 0.69 & 0.74 & 2.54 & 5.56 & 2.79 & 0.95 & 13.28 \\
\hline EGe1(kWh) & 1.06 & 1.35 & 1.24 & 0.17 & 1.46 & 2.29 & 7.57 \\
\hline EGe2 (kWh) & 0.69 & 0.74 & 0.34 & 0.67 & 0.86 & 0.91 & 4.21 \\
\hline VEG $(\%)$ & - & - & - & - & - & - & $44.38 \%$ \\
\hline EMe1 (kWh) & 0.00 & 0.00 & 1.01 & 3.96 & 1.45 & 0.00 & 6.41 \\
\hline EMe2 (kWh) & 0.00 & 0.00 & 0.59 & 1.79 & 0.67 & 0.00 & 3.05 \\
\hline VEM (\%) & - & - & - & - & - & - & $52.41 \%$ \\
\hline REPFe2 (\%) & - & - & - & - & - & - & $25.14 \%$ \\
\hline
\end{tabular}




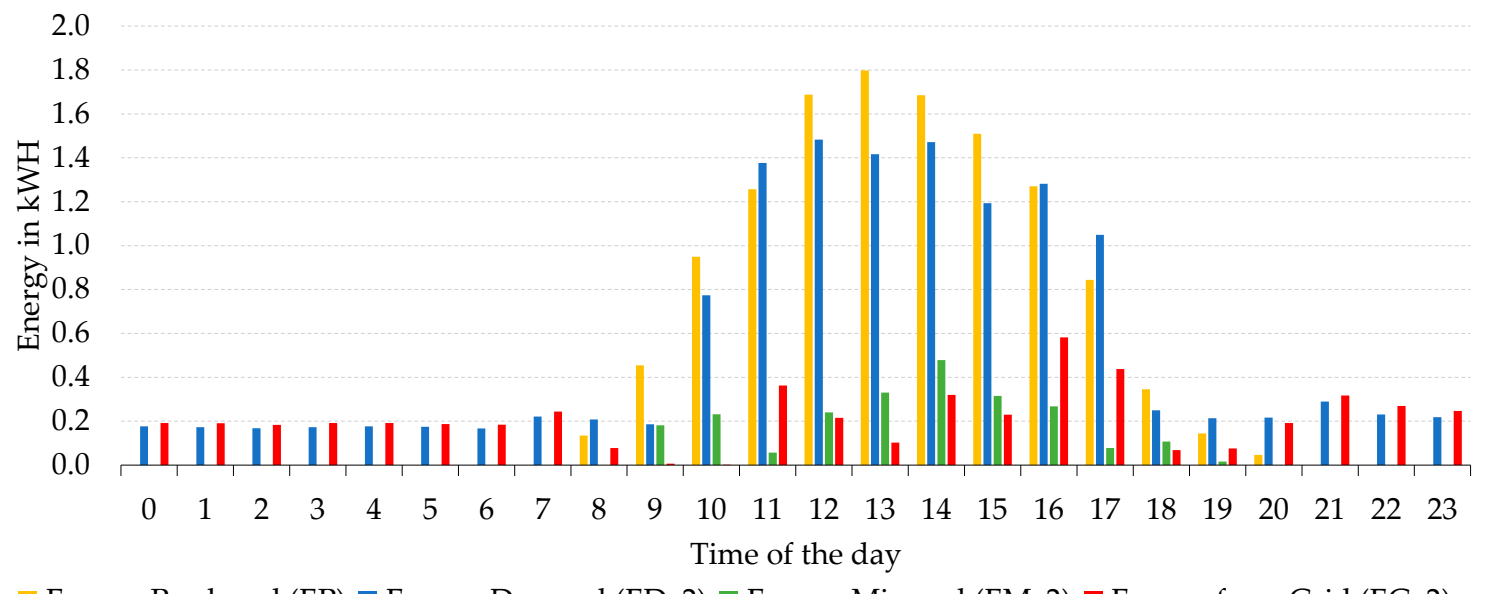

$\square$ Energy Produced (EP) $\square$ Energy Demand (EDe2) $\square$ Energy Misused (EMe2) $\square$ Energy from Grid (EGe2)

Figure 13. Hourly energy analysis of an average design day in scenario 2 in $\mathrm{kWh}$.

\subsubsection{Daily Energy Analysis in Scenario 2}

Figure 14 contains graph bars to show EP, EDe2, EGe2, and EMe2.

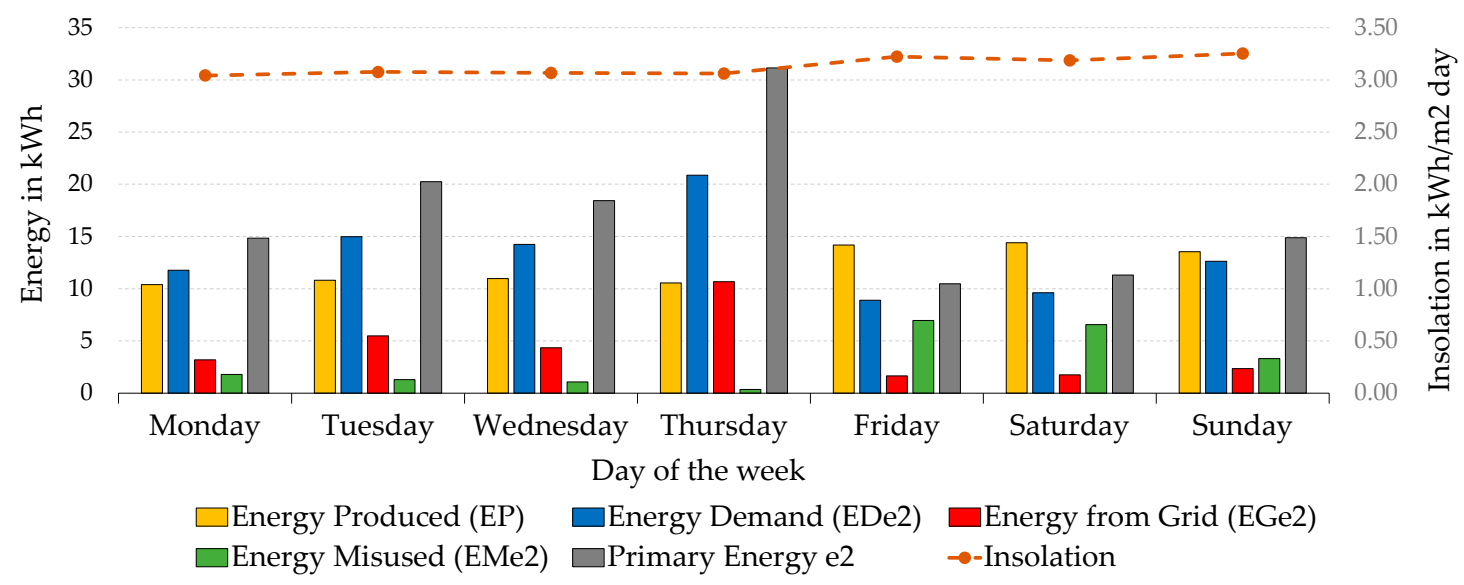

Figure 14. Daily energy analysis: EP, ED, EGe2, and EMe2 for scenario 2 in kWh.

The EP results do not vary since the PV array has not undergone any changes. Moreover, the amount of energy used per day (EDe2) remains invariable since rescheduling does not affect the full day ED. On the contrary, EG and EM have changed due to rescheduling techniques, from EGe1 to EGe2 and from EMe1 to EMe2. The average reduction on the primary energy demand for an average day and every day of the week is quite noticeable, as can be seen in Table 6.

Table 6. Daily energy analysis: Comparison between scenarios 1 and 2 in kWh.

\begin{tabular}{ccccccccc}
\hline $\mathbf{k W h}$ & Monday & Tuesday & Wednesday & Thursday & Friday & Saturday & Sunday & Average \\
\hline EP $(\mathrm{kWh})$ & 10.40 & 10.81 & 10.98 & 10.55 & 14.20 & 14.40 & 13.55 & 12.13 \\
ED $(\mathrm{kWh})$ & 11.79 & 14.97 & 14.25 & 20.87 & 8.88 & 9.60 & 12.62 & 13.28 \\
$\begin{array}{c}\text { Primary } \\
\text { Energy e1 } \\
\quad(\mathrm{kWh})\end{array}$ & 17.11 & 22.65 & 22.34 & 33.08 & 13.69 & 15.27 & 19.92 & 20.73 \\
$\begin{array}{c}\text { Primary } \\
\text { Energy e2 } \\
(\mathrm{kWh})\end{array}$ & 14.85 & 20.26 & 18.43 & 31.15 & 10.48 & 11.30 & 14.90 & 17.34 \\
\hline
\end{tabular}

Finally, there has been a reduction in the primary energy demand from $20.27 \mathrm{kWh} /$ day in scenario 1 to $17.34 \mathrm{kWh} /$ in scenario 2 , which also helps improve the energy performance of the buildings to 
fulfil the uhuMEBr primary energy criterion [30]. Table 7 shows a comparison of the primary energy demand per $\mathrm{m}^{2}$ according to uhuMEBr objectives.

Table 7. Summary of the primary energy demand in scenarios 1 and 2 on an average day.

\begin{tabular}{ccc}
\hline uhuMEBr & Scenario 1 $\mathbf{( k W h} / \mathbf{m}^{\mathbf{2}}$ day) & Scenario $\mathbf{2}\left(\mathbf{k W h} / \mathbf{m}^{\mathbf{2}}\right.$ day) \\
\hline Year: $80 \mathrm{kWh} / \mathrm{m}^{2}$ & Insufficient data & Insufficient data \\
Day: $0.22 \mathrm{kWh} / \mathrm{m}^{2}$ & 0.23 & 0.19 \\
\hline
\end{tabular}

\subsection{Users When to Use Guide}

According to the results obtained, When to Use labels have been proposed as a strategy to influence the occupants' behavior. These labels include operation advice about the best times to use appliances connected to circuits $\mathrm{C} 1, \mathrm{C} 6$, and C7, which can be rescheduled: The suggested labelling system can be seen in Appendix A.

\subsection{Energy Cost-Balance Analysis}

Table 8 includes an economic summary with a comparison between scenarios 1 and 2 . It shows that the cost for scenario 1 in the case of the new Electric Energy Self-Consumption standard [15] would have been approved at the time of the experimentation, and also a simulation considering similar prices per $\mathrm{kWh}$ for scenario 2. Prices do not include taxes, etc. Only the price of demand has been considered.

Table 8. Energy-cost balance analysis between scenarios 1 and 2. Taxes are not included.

\begin{tabular}{|c|c|c|c|c|c|c|}
\hline \multirow[t]{2}{*}{ Indicator/scenario } & \multicolumn{3}{|c|}{$\begin{array}{c}\text { Scenario 1 } \\
\text { (Energy Cost-Income/day) }\end{array}$} & \multicolumn{3}{|c|}{$\begin{array}{c}\text { Scenario } 2 \\
\text { (Energy Cost-Income/day) }\end{array}$} \\
\hline & $(\mathrm{kWh})$ & $(€ / \mathbf{k W h})$ & (€/day) & (kWh) & (€/kWh) & (€/day) \\
\hline ECGe1 & 7.57 & 0.129 & 0.98 & & - & \\
\hline ECGe2 & & - & & 4.21 & 0.129 & 0.54 \\
\hline EIMe1 & 6.41 & 0.052 & 0.33 & & - & \\
\hline EIMe2 & & - & & 3.05 & 0.052 & 0.16 \\
\hline Taxes, etc. & \multicolumn{6}{|c|}{ Not considered } \\
\hline $\begin{array}{l}\text { Electricity cost } \\
\quad(E G-E M)\end{array}$ & & & 0.65 & & & 0.38 \\
\hline Cost reduction & & & & & & $\begin{array}{c}0.27 \\
€ / \text { day } \\
58.46 \%\end{array}$ \\
\hline
\end{tabular}

The reduction from EGe1 to EGe2 produces a reduction in the daily cost for electricity from EUROS 0.98 to 0.54 per day at EGe2, while the reduction from EMe1 to EMe2 produces an income reduction from EUROS 0.33 to 0.16 per day. Therefore, the cost-benefit balance is reduced from EUROS 0.65 to 0.38 per day, which allows home tenants to reduce the cost of electricity demand by $58.46 \%$, thanks to the rescheduling suggested in the present paper.

\section{Discussion}

It makes no sense to talk about energy efficiency in buildings if comfort conditions cannot be guaranteed. This case study guarantees comfort according to uhuMEBr, to later proceed with an energy demand rescheduling that enables a reduction in the primary energy demand.

\subsection{Successful Comfort Performance}

According to the results shown in Section 3 (Figures 5 and 6), the uhuMEBr has been successful in achieving adequate comfort conditions. Interior $\mathrm{T}^{\circ}$ data prove that living and sleeping rooms both 
keep comfort conditions more than $95 \%$ of the time according to studies [33]. RH values are usually circa $70 \%$ within the sleeping room and circa $75 \%$ within the living room. As some studies suggest [27], this could produce some building pathologies and occupant's health issues if the RH levels remain so high for long periods of time. According to the climate definition, winter is the most humid season of the year in Huelva, therefore, the RH gathered would be the highest in the year. A study that includes the summer period would probably decrease RH under $60 \%$. Therefore, this concern would constitute a seasonal problem lasting several months of the year.

These comfort conditions have been obtained with an insignificant demand from HAC circuits. As seen in Figure 11, there was little need to use circuits C2 (HR) and C9 (HAC) to maintain comfort conditions. This is probably affected by local climate conditions, as well as due to the successful use of the uhuMEBr methodology, which takes advantage of occupation loads to maintain winter comfort. For further research, it would be interesting to research summer conditions and how overheating is solved.

Finally, it is obvious that comfort remains invariable when no rescheduling has been considered for the HVAC circuits: C2 and C9.

\subsection{Primary Energy Consumption in Scenario 1}

According to the results shown in figures and tables from Section 3.2.1, the solar PV array produces energy, which helps reduce ED. EP is affected by several factors including insolation, as well as the PV array efficiency that may bring variations in the daily amount of EP. Results in Table 3 show a certain grade of alignment between insolation and $\mathrm{EP}$, which is consistent with the experimentation methodology. However, ED is quite more irregular due to human participation and no patterns can be established with figures from $8.88 \mathrm{kWh}$ on Friday to $20.87 \mathrm{kWh}$ on Thursday. A higher occupation and extra activity of house staff, which cannot be accurately predicted, may be the reason for these irregularities. As a result of EP and EDe1, EGe1, EMe1, and the REPF are also quite irregular as seen in Table 3. Days with high EP and low ED have usually lower EG and higher EM, which was expected according to formulations (4) and (5), but it can also be influenced by hourly patterns such as those portrayed in Figure 8 and Table 6. When most of the ED is around midday, then EP is used more efficiently, and EG and EM are obviously reduced, as well as the REPF. For the week considered, the REPF has important deviations from $22.27 \%$ on Thursday to $74.17 \%$ on Saturday, as well as an average of $52.84 \%$, which provide interesting opportunities for energy coupling.

A deeper look into the hourly energy analysis is shown in Figure 6. EP shows a bell pattern typical of a winter day as seen in other studies $[14,23,24]$. Here, ED is quite irregular with higher numbers during the day and residual low numbers at night. When both ED and EP are combined, the solar PV production is higher than needed, which produces a mismatch between EP and ED. Then, results in EMe1 during the period from 10:30 to 17:30 and EGe1 for the rest of the time.

This extra energy, which has not been used by the dwelling can then be reused, via energy coupling improvement and by transferring energy back to the grid. The introduction of new regulations to the Spanish renewables market finally allows an effective utilization of RES to enhance the evolution from consumer to prosumer [16] for many dwelling tenants [17]. Energy coupling may bring easy and reasonable improvements in energy performance at a very low cost, as shown in the transition from scenario 1 to 2 .

The analysis of instant power graphs from Figures 9 and 10 demonstrates how PDe1 is distributed over a whole day and by circuit in Figure 11. Several studies [23,24,42-45] identify the control of electric circuits as a solution to increase energy coupling, but in all cases using complex and expensive smart appliances, as well as building monitoring and control facilities, which is not the aim of this study. In Figure 11, C1 (DHW), C6 (COOK), C7 (WASH), and C8 (FRIDGE) provide the highest instant power values, but C8 (FRIDGE) cannot be rescheduled according to its own characteristics. This suggests that the improvement of energy efficiency on fridges, as well as an adequate equipment sizing, are important to help with primary energy reduction. 
Finally, those circuits can be grouped as ones that can be rescheduled or not (see Figure 12). Circuits C1, C6, and C7 (PSe1) produce the most significant part of EDe1, with an irregular PDe1 that can be easily rescheduled with the participation of tenants. The rest of the circuits (POe1) have a very regular and low profile. Therefore, these circuits can only be improved by the use of more complex, expensive devices $[23,25,42]$. The power of PSe1 shows a peak value of circa $1000 \mathrm{w}$, while the POe1 has a constant value of $200 \mathrm{~W}$ most of the time, in which both can be supplied by PP through the PV array at peak production. Therefore, the current situation in scenario 1 can mostly be improved by rescheduling several electric circuits.

It is yet unclear if this irregularity would remain during the rest of the year or not. However, it may be necessary to proceed with further data collection to include summer conditions, in order to obtain a full year picture profile.

\subsection{Primary Energy Consumption in Scenario 2}

Scenario 2 is defined as a realistic and affordable way of improving energy coupling via hourly ED modification, which seems very promising according to Figures 13 and 14 . Some promising research by other authors based on renewable energy storage [44,45], as well as smart appliances and/or algorithm controls [23,24,42], can achieve similar success. However, they all need a more significant economic investment. On the contrary, the methodology proposed in this paper is based solely in timer controls and the occupant's education through the proper management of information with When to Use labels posted on specific appliances. It may be a more difficult strategy to develop in a wider range of circuits, however, they certainly represent a very low PD in comparison with C1, C6, and C7. Kakran et al. [24] described the economic benefits of solar energy production, energy back to grid, smart appliances with electronic control scheduling, and "time of use" tariffs, which provided a reduction circa $70 \%$, while this research suggests an average reduction from scenario 1 to 2 of $58.46 \%$ with the suggested rescheduling, plus energy back to the grid without an electronic control (see Table 8). Additionally, it would have been interesting to provide a scenario 0 , where no PV array is installed to compare with those results from Kakran et al. [24].

Figure 13 contains the hourly energy breakdown after rescheduling simulation, where EDe2 and EP show a very similar pattern, while EGe2 and EMe2 have been reduced over the whole day. According to Table 5, scenario 2 has provided an average reduction of $44.38 \%$ on EG and $52.41 \%$ on EM. Furthermore, it produces an average reduction on the REPF from 52.84\% REPFe1 to $25.14 \%$ REPFe2. A $25.14 \%$ energy exchange back to the grid is suggested since it cannot be used even after the rescheduling of $\mathrm{C} 1, \mathrm{C} 6$, and C7. However, it is necessary to say, that although this energy exchange is interesting as a secondary option, it brings several difficulties to grid management, which should be considered at a bigger scale [43] such as transportation losses, peak voltage, and planning needs. Finally, the daily energy analysis in scenario 2 can be seen in Figure 14 and Table 6, which shows the benefits of the rescheduling applied.

In case EP is used on-site, energy transportation becomes unnecessary, therefore, the conversion factor considered in Equations (6)-(8) to determine the primary energy from EP is 1, rather than 1.964. In this case, EP is helping reduce the primary energy even when ED remains the same. Therefore, results show that scenario 2 can help fulfill the uhuMEBr $[30,32]$ with a reduction in the primary energy demand from 0.23 to $019 \mathrm{kWh} / \mathrm{m}^{2}$ per day, which is slightly better than the limit established at $0.22 \mathrm{kWh} / \mathrm{m}^{2}$ day. UhuMEB and uhuMEBr provide the same primary energy demand limit for both new and rehabilitated buildings, which is more difficult in the case of the latter. The reduction in electricity cost provided by scenario $2,58.46 \%$ before taxes, increases the effectiveness of the When to Use information system, therefore, the participation of the occupants.

Although this research has succeeded in reducing the primary energy demand, several improvements could still be done to increase this reduction. EDe2 from electric circuit $\mathrm{C} 1$, could have been reduced further with the installation of a thermal solar RES, or the installation of an aerothermal high-efficiency heat pump, rather than the existing water heater. A specific electric circuit with DC could 
have been introduced for those electronic devices with batteries, or even more in the case of detached houses with a parking space that enables charging vehicles on-site during the day. Additionally, it is important to consider that this would probably be slightly different in summer when EP graphs change from the current bell pattern to an extended version from early morning to late night. Then, EM would obviously be higher and the energy back to grid would be more necessary. Therefore, the energy back to grid becomes more important.

\section{Conclusions}

This paper is based on the results obtained from a monitoring system installed in a rehabilitated social dwelling in a subtropical location for two different scenarios. The dwelling includes a RES facility to produce renewable energy on-site but most of the EP is generated around the midday. Therefore, most of the solar energy is misused.

The research conducted proposes a strategy based on rescheduling the energy demand to take maximum advantage of the RES on-site and energy back to grid strategy, rather than installing an ESS, since it is expensive and requires additional maintenance.

The analysis done demonstrates that rehabilitation achieved a high grade of success in both: Comfort levels and low primary energy demand, according to the uhuMEBr methodology limits. The primary energy demand was reduced from 0.23 to $0.19 \mathrm{kWh} / \mathrm{m}^{2}$ day, which represents less than $80 \mathrm{kWh} / \mathrm{m}^{2}$ year if the strategies were extended throughout the whole year. Additionally, the reduction in EG provides a lower electricity cost with a $58.46 \%$ monthly reduction for a typical winter week.

The experimentation was conducted during the weeks of the year with the lowest solar insolation. Therefore, it can be extended to the rest of the year for dwellings in similar locations.

This paper concludes that among other strategies, which can be more complex, the simple introduction of timers and adequate education for occupants can highly help reschedule those electricity circuits that demand more energy at home: DHW (C1), cooking (C6), and washing (C7). Rescheduling only these three electric circuits increases the usability of the renewable solar energy produced on-site, reducing the REPF from $52.84 \%$ in scenario 1 to $25.14 \%$ in scenario 2 . This contributes significantly in improvement from a near zero energy building (nZEB) to a real zero energy building (ZEB) or even a building that produces more energy than it consumes (+ZEB). Additionally, this produces an important reduction in electricity costs.

Further improvements could be done in future research to further reduce the primary energy demand, such as the introduction of specific DC circuits for electronics [26], the replacement of the current electric heater for a thermal solar energy system as the primary energy source for water heating at DHW and washing appliances, as well as the introduction of natural lighting sensors to control the electric lighting system. Moreover, it would be convenient to proceed with further research of the dwelling performance under summer conditions and the experimental validation of rescheduling techniques.

Author Contributions: S.G.M. conceived the idea and experimentation, checked the manuscript, and carried out the revision; A.S.C. wrote the article and made the corrections; M.V.R. carried out the experimentation; J.M.A.M. supervised and reviewed all the work and the manuscript. All authors have read and agreed to the published version of the manuscript.

Funding: This work has been funded by the DPI2017-85540-R Project supported by the Spanish Ministry of Economy and Competitiveness and by the European Union Regional Development Fund. Some parts of the study have been funded by the resources of the research team "Control y Robótica (TEP192)" from the University of Huelva (Spain). It was also partially supported by the project dode G-GI3000/IDI_TEP192 of the Andalusia regional government (Spain).

Conflicts of Interest: The authors declare no conflict of interest. 


\section{Abbreviations}

\begin{tabular}{|c|c|}
\hline $\mathrm{AC}$ & Alternating current \\
\hline DC & Direct current \\
\hline DHW & Domestic Hot Water \\
\hline E & Energy \\
\hline ECG & Energy cost from grid \\
\hline EIM & Energy income from misused \\
\hline ED & Energy demand \\
\hline EG & Energy from grid \\
\hline EM & Energy misused \\
\hline EP & Energy produced \\
\hline ESS & Energy storage system \\
\hline GHC & Greenhouse gas \\
\hline HAS & Home Automation System \\
\hline HAC & Heating and Air Conditioning \\
\hline $\mathrm{HR}$ & Heat recovery \\
\hline I & Current intensity \\
\hline MEB & Minimum energy buildings \\
\hline $\mathrm{P}$ & Electric power \\
\hline PF & Power factor \\
\hline PD & Power demand \\
\hline PG & Power from grid \\
\hline PM & Power misused \\
\hline $\mathrm{PP}$ & Power produced \\
\hline $\mathrm{PO}$ & Power others than scheduled \\
\hline PS & Power scheduled \\
\hline PV & Photovoltaic \\
\hline REPF & Renewable energy potential factor \\
\hline RES & Renewable Energy System \\
\hline $\mathrm{RH}$ & Relative Humidity \\
\hline $\mathrm{T}$ & Dry Bulb Temperature \\
\hline Tud & Average Dry Bulb Temperature for upward and downward measurements \\
\hline uhuMEB & University of Huelva Minimum Energy Buildings \\
\hline uhuMEBr & University of Huelva Minimum Energy Buildings for retrofit \\
\hline $\mathrm{V}$ & Voltage \\
\hline VEG & Variation of energy from grid \\
\hline VEM & Variation of energy misused \\
\hline VOC & Volatile organic compounds \\
\hline ZEB & Zero Energy Building \\
\hline
\end{tabular}




\section{Appendix A}

\section{WHEN TO USE WINTER SEASON ENERGY SAVING TIPS FOR GREEN HOMES}

This home is equipped with PV modules to produce free clean energy.

Remember, this production is higher in the daytime, between 10:30 and 17:30.

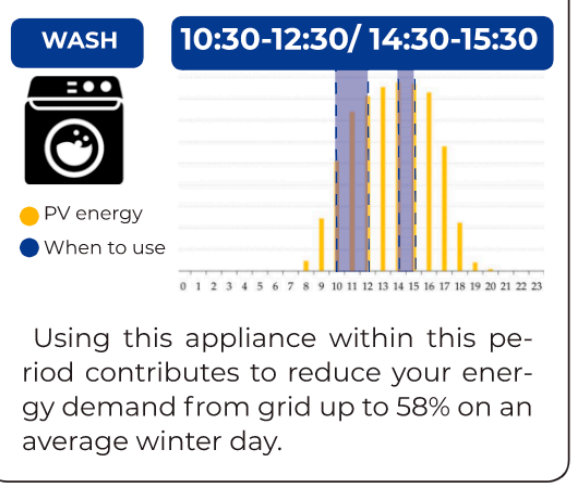

\section{WHEN TO USE WINTER SEASON ENERGY SAVING TIPS FOR GREEN HOMES}

This home is equipped with PV modules to produce free clean energy.

Remember, the production is higher in the daytime, between 10:30 and 17:30.

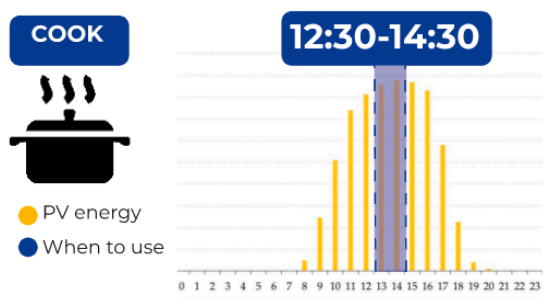

Using this appliance within this period contributes to reduce your energy demand from grid up to $58 \%$ on an average winter day.

\section{WHEN TO USE WINTER SEASON ENERGY SAVING TIPS FOR GREEN HOMES}

This home is equipped with PV modules to produce free clean energy. Remember, this production is higher in the daytime, between 10:30 and 17:30

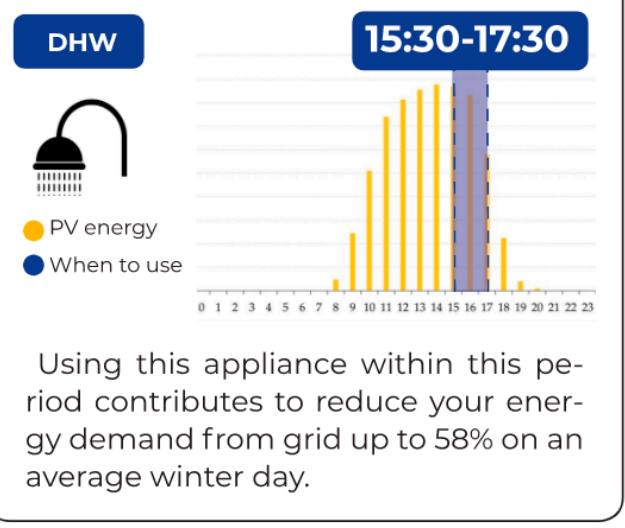

Figure A1. Prototypes for When to Use labels. 


\section{References}

1. Huang, L.; Krigsvoll, G.; Johansen, F.; Liu, Y.; Zhang, X. Carbon emission of global construction sector. Renew. Sustain. Energy Rev. 2018, 81, 1906-1916. [CrossRef]

2. Levermore, G.J. A review of the IPCC Assessment Report Four, Part 1: The IPCC process and greenhouse gas emission trends from buildings worldwide. Chart. Inst. Build. Serv. Eng. 2008, 29, 349-361. [CrossRef]

3. Cordero, A.S.; Melgar, S.G.; Márquez, J.M.A. Green building rating systems and the new framework level(s): A critical review of sustainability certification within Europe. Energies 2019, 13, 1-26.

4. Sartori, I.; Hestnes, A.G. Energy use in the life cycle of conventional and low-energy buildings: A review article. Energy Build. 2007, 39, 249-257. [CrossRef]

5. European Community. Directive 2009/28/EC of the european parliament and of the council of 23 April 2009 on the promotion of the use of energy from renewable sources and amending and subsequently repealing Directives 2001/77/EC andâ2003/30/EC. Off. J. Eur. Union. 2009, 5, 16-62.

6. Haas, R.; Panzer, C.; Resch, G.; Ragwitz, M.; Reece, G.; Held, A. A historical review of promotion strategies for electricity from renewable energy sources in EU countries. Renew. Sustain. Energy Rev. 2011, 15, 1003-1034. [CrossRef]

7. Márquez, J.M.A.; Bohórquez, M.Á.M.; Melgar, S.G. Ground thermal diffusivity calculation by direct soil temperature measurement. application to very low enthalpy geothermal energy systems. Sensors 2016, 16, 306. [CrossRef]

8. Zhou, H.; Lu, Y.; Liu, X.; Chang, R.; Wang, B. Harvesting wind energy in low-rise residential buildings: Design and optimization of building forms. J. Clean. Prod. 2017, 167, 306-316. [CrossRef]

9. Pillai, G.G.; Putrus, G.A.; Georgitsioti, T.; Pearsall, N.M. Near-term economic benefits from grid-connected residential PV (photovoltaic) systems. Energy 2014, 68, 832-843. [CrossRef]

10. Dusonchet, L.; Telaretti, E. Comparative economic analysis of support policies for solar PV in the most representative EU countries. Renew. Sustain. Energy Rev. 2015, 42, 986-998. [CrossRef]

11. Cucchiella, F.; D'Adamo, I.; Gastaldi, M.; Stornelli, V. Solar photovoltaic panels combined with energy storage in a residential building: An economic analysis. Sustainability 2018, 10, 3117. [CrossRef]

12. Cucchiella, F.; D'Adamo, I.; Gastaldi, M. Economic analysis of a photovoltaic system: A resource for residential households. Energies 2017, 10, 814. [CrossRef]

13. Cucchiella, F.; D'Adamo, I.; Gastaldi, M. Photovoltaic energy systems with battery storage for residential areas: An economic analysis. J. Clean. Prod. 2016, 131, 460-474. [CrossRef]

14. Ordóñez, J.; Jadraque, E.; Alegre, J.; Martínez, G. Analysis of the photovoltaic solar energy capacity of residential rooftops in Andalusia (Spain). Renew. Sustain. Energy Rev. 2010, 14, 2122-2130. [CrossRef]

15. Ministerio Para LA Transición Ecológica. Real Decreto 244/2019, de 5 de abril, por el que se regulan las condiciones administrativas, técnicas y económicas del autoconsumo de energía eléctrica. Boletín Ofcial Del Estado 2019, 35674. Available online: https://www.boe.es/diario_boe/txt.php?id=BOE-A-2019-5089 (accessed on 28 September 2020).

16. Toffler, T.; Alvin, A. The Third Wave; Bantam Books: New York, NY, USA, 1980.

17. Arboleya, P.; Koirala, A.; Suarez, L.; Mohamed, B.; Gonzalez-Moran, C. Impact Evaluation of the New Self-Consumption Spanish Scenario on the Low-Voltage Terminal Distribution Network. IEEE Trans. Ind. Appl. 2019, 55, 7230-7239. [CrossRef]

18. Garcia-Garre, A.; Gabaldon, A.; Alvarez-Bel, C.; Ruiz-Abellon, M.; Guillamon, A. Integration of Demand Response and Photovoltaic Resources in Residential Segments. Sustainability 2018, 10, 3030. [CrossRef]

19. IDAE. Factores de Emisión de CO2 y Coeficientes de Paso a Energía Primaria de Diferentes Fuentes de Energía Final Consumidas en el Sector de Edificios en España; Ministerio de Industria, Energía y Turismo: Madrid, Spain, 2016; Available online: http://www.minetad.gob.es/energia/desarrollo/EficienciaEnergetica/RITE/Reconocidos/ Reconocidos/Otrosdocumentos/Factores_emision_CO2.pdf (accessed on 28 September 2020).

20. Vieira, F.M.; Moura, P.S.; de Almeida, A.T. Energy storage system for self-consumption of photovoltaic energy in residential zero energy buildings. Renew. Energy 2017, 103, 308-320. [CrossRef]

21. Mohammadnezami, M.H.; Ehyaei, M.A.; Rosen, M.A.; Ahmadi, M.H. Meeting the electrical energy needs of a residential building with a wind-photovoltaic hybrid system. Sustainability 2015, 7, 2554-2569. [CrossRef]

22. Aghaei, J.; Alizadeh, M.I. Demand response in smart electricity grids equipped with renewable energy sources: A review. Renew. Sustain. Energy Rev. 2013, 18, 64-72. [CrossRef] 
23. Bejoy, E.; Islam, S.N.; Oo, A.M.T. Optimal scheduling of appliances through residential energy management. In Proceedings of the 2017 Australasian Universities Power Engineering Conference (AUPEC), Melbourne, Australia, 19-22 November 2017; pp. 1-6.

24. Kakran, S.; Chanana, S. Energy scheduling of residential community equipped with smart appliances and rooftop solar. In Proceedings of the 2017 7th International Conference on Power Systems (ICPS), Pune, India, 21-23 December 2017; pp. 323-327.

25. Qayyum, F.A.; Naeem, M.; Khwaja, A.S.; Anpalagan, A. Appliance scheduling optimization in smart home networks comprising of smart appliances and a photovoltaic panel. In Proceedings of the 2015 IEEE Electrical Power and Energy Conference (EPEC), London, UK, 26-28 October 2015; pp. 457-462.

26. Glasgo, B.; Azevedo, I.L.; Hendrickson, C. How much electricity can we save by using direct current circuits in homes? Understanding the potential for electricity savings and assessing feasibility of a transition towards DC powered buildings. Appl. Energy 2016, 180, 66-75. [CrossRef]

27. Kottek, M.; Grieser, J.; Beck, C.; Rudolf, B.; Rubel, F. World map of the Köppen-Geiger climate classification updated. Meteorol. Z. 2006, 15, 259-263. [CrossRef]

28. Ministerio de Vivienda. Real decreto 314/2006. Código Técnico Edificación; Ministerio de Vivienda: Madrid, Spain, 2006; Volume 6259, p. 11.

29. Gangolells, M.; Casals, M.; Forcada, N.; MacArulla, M.; Cuerva, E. Energy mapping of existing building stock in Spain. J. Clean. Prod. 2016, 112, 3895-3904. [CrossRef]

30. Melgar, S.G.; Bohórquez, M.Á.M.; Márquez, J.M.A. uhuMEBr: Energy Refurbishment of Existing Buildings in Subtropical Climates to Become Minimum Energy Buildings. Energies 2020, 13, 1204. [CrossRef]

31. Márquez, J.M.A.; Bohórquez, M.Á.M.; Melgar, S.G. A New Metre for Cheap, Quick, Reliable and Simple Thermal Transmittance (U-Value) Measurements in Buildings. Sensors 2017, 17, 2017. [CrossRef] [PubMed]

32. Melgar, S.G.; Bohórquez, M.Á.M.; Márquez, J.M.A. UhuMEB: Design, construction, and management methodology of minimum energy buildings in subtropical climates. Energies 2018, 11, 2745. [CrossRef]

33. Nicol, J.F.; Humphreys, M.A. Adaptive thermal comfort and sustainable thermal standards for buildings. Energy Build. 2002, 34, 563-572. [CrossRef]

34. U.S. Environmental Protection Agency. A brief guide to mold, moisture and your home. In Indoor Work and Living Environments: Health, Safety and Performance; Agency Office of Air and Radiation Indoor Environments Division: Washington, DC, USA, 2009; pp. 307-318.

35. Butcher, K. Environmental Design 2015: CIBSE Guide A; Chartered Institution of Building Services Engineers: Balham, UK, 2015; Volume 195.

36. Islam, M.S.; Chowdhury, N.A.; Sakil, A.K.; Khandakar, A.; Iqbal, A.; Abu-Rub, H. Power quality effect of using incandescent, fluorescent, CFL and LED lamps on utility grid. In Proceedings of the 2015 First Workshop on Smart Grid and Renewable Energy (SGRE), Doha, Qatar, 22-23 March 2015.

37. Pipattanasomporn, M.; Kuzlu, M.; Rahman, S.; Teklu, Y. Load profiles of selected major household appliances and their demand response opportunities. IEEE Trans. Smart Grid 2014, 5, 742-750. [CrossRef]

38. Fortenbery, B. Power Factor Requirements for Electronic Loads in California rectifier Switch Mode Power Supply DC. In Proceedings of ACEEE Summer Study on Energy Efficiency in Buildings; The Next Generation: Reaching for High Energy Savings: Asilomar, CA, USA, 2014; pp. 160-170.

39. OMIE. Evolución del Mercado de Energía Eléctrica. Enero 2019. Informe Mensual ENERO 2019. 2020. Available online: https://www.omie.es/sites/default/files/publications/informe_mensual_enero_esp_5_0.pdf (accessed on 28 September 2020).

40. Ashrae, A. Standard 55-2004, Thermal Environmental Conditions for Human Occupancy, Atlanta: American Society of Heating, Refrigerating, and Air-Conditioning Engineers; American Society of Heating Refrigeration and Air Conditioning Engineers: Atlanta, GA, USA, 2004.

41. ASHRAE. American Society of Heating, Refrigerating. In Standard 62.1-2016, Ventilation for Acceptable Indoor Air Quality; American Society of Heating Refrigeration and Air Conditioning Engineers: Atlanta, GA, USA, 2016.

42. Garroussi, Z.; Ellaia, R.; Talbi, E.G. Appliance scheduling in a smart home using a multiobjective evolutionary algorithm. In Proceedings of the 2016 International Renewable and Sustainable Energy Conference (IRSEC), Marrakech, Morocco, 14-17 November 2016; pp. 1098-1103.

43. Nistor, S.; Wu, J.; Sooriyabandara, M. The impact and opportunities of smart appliances on distribution networks. In Proceedings of the IEEE PES ISGT Europe 2013, Lyngby, Denmark, 6-9 October 2013; pp. 1-4. 
44. Wang, X.; Palazoglu, A.; El-Farra, N.H. Operational optimization and demand response of hybrid renewable energy systems. Appl. Energy 2015, 143, 324-335. [CrossRef]

45. Korkas, C.D.; Baldi, S.; Michailidis, I.; Kosmatopoulos, E.B. Occupancy-based demand response and thermal comfort optimization in microgrids with renewable energy sources and energy storage. Appl. Energy 2016, 163, 93-104. [CrossRef]

Publisher's Note: MDPI stays neutral with regard to jurisdictional claims in published maps and institutional affiliations.

(C) 2020 by the authors. Licensee MDPI, Basel, Switzerland. This article is an open access article distributed under the terms and conditions of the Creative Commons Attribution (CC BY) license (http://creativecommons.org/licenses/by/4.0/). 